\title{
Suction caissons in dense sand, Part II: Vertical cyclic loading into tension
}

Manuscript submitted to Géotechnique on 2 November 2016,

revision 2 submitted on 13 July 2017 by:

\section{Britta Bienen (corresponding author) *}

8 Senior Lecturer

9 Tel: +61(0) 864884246

10 Email: britta.bienen@uwa.edu.au

Rasmus Tofte Klinkvort ${ }^{+}$

14

15

16

Senior consultant

Email: rtk@ngi.no

\section{Conleth O'Loughlin *}

Associate Professor

Email: conleth.oloughlin@uwa.edu.au

\section{Fangyuan Zhu *}

$\mathrm{PhD}$ candidate

Email: fangyuan.zhu@ research.uwa.edu.au

\section{Byron W. Byrne \#}

Professor

Email: byron.byrne@eng.ox.ac.uk

* Centre for Offshore Foundation Systems

The University of Western Australia

35 Stirling Hwy

Crawley, Perth, WA 6009

Australia

Fax: +61 (0) 864881044

${ }^{+}$Norwegian Geotechnical Institute

Sognsveine 72

0855 Oslo

Norway

39

$40 \quad$ \# Department of Engineering Science

41 The University of Oxford

42 Parks Road, Oxford, OX1 3PJ

43 UK 


\section{ABSTRACT}

47 Suction caissons have been used for numerous oil and gas installations and are 48 increasingly considered as a foundation solution for offshore wind turbines (OWT). There 49 can be significant differences between the two offshore energy applications in the load 50 paths and magnitudes, soil type and caisson aspect ratio (skirt length to diameter). This 51 paper investigates the response of suction caissons in dense sand to a range of cyclic 52 vertical loading histories relevant to a jacket supported OWT, with an emphasis on cyclic 53 tensile loading. The findings are based on a series of experiments performed in a 54 centrifuge, such that soil stresses reflect those in the prototype. The caisson was installed 55 using suction at enhanced gravity, followed by cyclic loading and then caisson extraction. 56 The installation and extraction results are discussed in a companion paper. This paper 57 focuses on the caisson load-displacement response under vertical cyclic loading. The 58 centrifuge experimental results reinforce findings from previous work, add insights into 59 the load transfer mechanisms and provide confidence of their applicability to the 60 prototype, both qualitatively and quantitatively. The results highlight the complexity of 61 the caisson response, particularly under tensile loading, with the influences of average 62 load, cyclic load amplitude, and drainage discussed in detail.

65 Key words: Suction caisson; cyclic loading; offshore engineering; centrifuge modelling; 66 sand. 


\section{INTRODUCTION}

The design and response of suction caissons as foundations for offshore wind turbines (OWTs) has been the focus of much research over the past twenty years. Trial offshore wind turbine structures on suction caissons have been installed, with the first offshore wind farms using suction caisson foundations on a commercial scale now in the design phase. The companion paper, Bienen et al. (2017), provides background information on this topic and explores the issues of installation, effect of the pumping rate on subsequent caisson response, drainage, and finally the limiting capacity in tension. This second paper explores the effect of load cycles into tension. This is critical, particularly for multicaisson foundation systems, where the limiting design condition might be the lightly loaded windward caisson. Changes in vertical loading from the OWT self-weight that is evenly distributed amongst all caissons arise due to the push-pull mechanism between windward and leeward caissons in response to overturning moment resulting from wind, wave and current action on the OWT (Fig. 1). The design of the windward caisson, in combination with the structural weight, determines the caisson spacing. A greater foundation footprint in order to minimise or eliminate tensile loading on the windward caisson leads inevitably to an increase in costs.

There is a substantial database of testing (including Byrne, 2000; Byrne and Houlsby 2002; 2004; Houlsby et al., 2005; 2006; Kelly et al., 2006b; Senders, 2008), in both compression and tension, for suction caissons, with the principal findings being:

- A change in the stiffness of response as the caisson moves from compression to tension during cycling, with significant flexibility of the response in tension.

- Net settlement, even when cyclic loading into tension is applied, if the average stress is sufficiently compressive.

- Significant tensile capacity under fast loading rates, which is reinforced by the results described by Bienen et al. (2017). This tensile capacity is mobilised at an upward displacement that is approximately $10 \%$ of the caisson diameter.

- Serviceability is the critical design criterion.

In order to limit displacements to acceptable values, the general approach has been to limit tensile loading to the frictional capacity, and take no account of the end bearing except under exceptional loading conditions (Houlsby, 2016). 
100

101 Much of the previous work (e.g. Kelly et al., 2006b) has taken place at small scale on the laboratory floor where the drained frictional capacity is relatively small in magnitude because of the low self-weight effective stresses in the soil. The trigger of the more flexible caisson response under tension has therefore been difficult to explore in detail, and given the difficulties of scaling of all key features in the $1 \mathrm{~g}$ model, the transfer of the findings to the prototype (in particular quantitatively) is complex.

In the design problem, the lightly loaded windward caisson will be operating at a significantly lower vertical load (as shown in Fig. 1c) compared to that during perfectly calm weather (i.e. with the self-weight evenly distributed between the caissons and no push-pull mechanism as shown in Fig. 1b). In addition, it is likely that the wind and wave direction will vary in time so that the lightly loaded windward caisson may differ from time to time. In these situations the caisson will have experienced a previous compressive load greater than the average load to which it might be exposed in the critical loading condition. In the small scale experiments (Kelly et al., 2006b), the loading amplitudes were increased as the test proceeds, so that the system was not operating in a "pre-loaded" state. This is a much more onerous loading condition than the likely in-service condition, which deserves further investigation.

To develop better insight into the tensile response of suction caissons, experiments were conducted in a geotechnical centrifuge, to ensure that stress levels reflect those of the prototype. Initially this paper provides a detailed comparison of the centrifuge experimental results with corresponding data obtained from small scale tests in a pressure chamber (Kelly et al., 2006b). This provides context with the existing database from the literature, before extending it through a wide-ranging investigation of behaviour under tensile loading at appropriate stress levels. This methodology creates a link to published data, provides greater confidence in the qualitative findings and enables quantitative translation of the model scale response to full scale. The comparison therefore adds significant value in bridging between this series of centrifuge tests, which is substantial in its own right, and the wider published database. 
132 The cyclic testing reflected loading on the individual caissons supporting a tripod jacket

133 structure, particularly the windward caisson. Detailed consideration of caisson load paths

134 has identified the most relevant loading scenarios to be explored (with details of the 135 background provided in Bienen et al., 2017), particularly with low average stresses

136 (around zero), comparable in magnitude to the frictional capacity. This is a significant 137 difference to previous testing of caissons in sand (Kelly et al., 2006b). The use of suction 138 installation is also different to some of the previous testing programs where the caissons 139 have been jacked or pushed in (Byrne, 2000; Byrne and Houlsby 2002; 2004; Houlsby et 140 al., 2005; 2006; Kelly et al., 2006b). The changes in the soil state and radial stresses due 141 to the installation method has been shown for piles (Henke, 2013) and differences in 142 penetration resistance have been documented for jacked and suction installed caissons 143 (Tran, 2005; Senders, 2008). For this series of centrifuge tests, a number of cyclic loading 144 histories were developed to reflect simplified 3 - 9 hour storm events. Tables 1 and 2 145 provide the overview of the cyclic loading history of the tests discussed in this paper. LC2 146 to LC9 maintain compressive average loads but cycle into tension, with a constant 147 average stress and cyclic amplitude increasing in each subsequent packet of loading. 148 LC10 and LC11 are similar to the load history described by the Hansteen (1981) 149 experiments and the model tests performed by Kelly et al. (2006b), respectively.

151 This paper presents a detailed discussion of the centrifuge experimental results to explore 152 effects of drainage, cyclic loading amplitude and average stress of a suction caisson in 153 dense sand, to conclude with implications for practice.

\section{RESULTS AND DISCUSSION}

156 A full description of the experiments and scaling considerations is provided in Bienen et 157 al. (2017), but in brief involved in-flight installation of a suction caisson (with diameter, $158 \mathrm{D}=80 \mathrm{~mm}$, skirt length, $\mathrm{L}=40 \mathrm{~mm}$, skirt thickness, $\mathrm{t}=0.5 \mathrm{~mm}$ ) into Baskarp sand with 159 a relative density, $D_{\mathrm{r}}=98 \pm 1 \%$, at $100 \mathrm{~g}$. The sand was saturated with pore fluids having 160 a viscosity 100 and 660 times that of water to generate differing drainage responses during 161 installation and loading. All tests considered in this paper had the same installation 162 history, with self-weight installation followed by suction installation at a pumping rate of 
$163392.7 \mathrm{~mm}^{3} / \mathrm{s}$ (model scale, with the choice of flow rate and installation response discussed in Bienen et al., 2017).

166 The experimental results are presented in normalised form, using stress, $V / A$, where $V$ is

167 the vertical load and $A$ is the plan caisson area, and, normalised displacement $z / L$, where $168 z$ is the skirt penetration depth and $L$ is the skirt length. The change in vertical 169 displacement is represented by $\Delta \mathrm{z} / \mathrm{L}$, the change in displacement relative to the 170 installation embedment. Total stress is denoted $\sigma$, excess pore pressure $\Delta \mathrm{u}$, with measured 171 values relating to the lid invert. As this paper focuses on the effect of cyclic loading into 172 the tensile region, a suitable reference load is the tensile drained frictional capacity of the 173 caisson, which depends on the skirt embedment, the sand relative density and the 174 mobilised friction angle at the skirt-soil interface. The caisson installation and cyclic 175 loading history plays a role in the resulting frictional tensile capacity (Bienen et al., 2017). 176 At full skirt embedment, the drained frictional tensile capacity of this caisson with an 177 aspect ratio $\mathrm{L} / \mathrm{D}=0.5$ (where $\mathrm{D}$ is the caisson diameter) in very dense Baskarp sand $178\left(D_{r}=98 \%\right)$ was established to be around $15 \mathrm{kPa}$ for $z / L=1$ (Bienen et al., 2017).

\section{Comparison with previous model tests on caissons under vertical cyclic loading}

181 The testing programme was planned carefully to provide new insights, but also to link closely with the existing database. Results of a small number of tests at prototype stress

183 levels with appropriately modified pore fluid viscosity in the centrifuge can thus validate a larger body of existing findings.

186 The loading history (Table 2) identified by Kelly et al. (2006b) for model testing in a 187 pressure chamber was selected for this purpose. These loading conditions reflect severe metocean conditions, with large amplitude excursions into tension from relatively high average stress levels, relevant to the heavily loaded leeward caisson(s). For these tests the model caisson had a diameter $\mathrm{D}=280 \mathrm{~mm}$ and a skirt length $\mathrm{L}=180 \mathrm{~mm}$. The caissons were jacked into the soil rather than installed by suction. Two soils were used: (i) Redhill

192110 sand at a relative density of $80-82 \%$ with a loading frequency of $1 \mathrm{~Hz}$ and (ii) 193 Oakamoor HPF5 sand with a relative density of 53-73\% at $1 \mathrm{~Hz}$ and $10 \mathrm{~Hz}$. The particle 194 size distributions of the Redhill and Oakamoor sands are provided in the companion paper 
195 (Bienen et al., 2017), with that of Redhill being similar to the Baskarp sand used in the

196

197

198

199

200

201

202

203

204

205

206

207

208

209

210

211

212

213

214

215

216

217

218

219

220

221

222

223

224

225

226 centrifuge tests. The estimated permeability of the two sands differed by three orders of magnitude, with estimates of $5 \times 10^{-4} \mathrm{~m} / \mathrm{s}$ for Redhill 110 and $5 \times 10^{-7} \mathrm{~m} / \mathrm{s}$ for Oakamoor HPF5. The soil samples were saturated with water.

Figures 2 and 3 compare the pressure chamber test results with those obtained in the centrifuge (with two different pore fluid viscosities) under a similar loading regime. It is worth noting that the achieved loads did not always match the target loads; for example the test in Oakamoor sand at $10 \mathrm{~Hz}$ (Fig. 2c and d) did not go into tension due to limitations with the feedback control. This was also true for the centrifuge tests performed at a loading rate of $0.5 \mathrm{~Hz}$ (Figs. 3a and c, with target and actual loads provided in Table 2). Consequently, these tests were repeated at $0.25 \mathrm{~Hz}$ (Figs. $3 \mathrm{~b}$ and d) with much better load control such that tensile loads were achieved in packets with large amplitudes. The difference in the permanent displacements (Fig. 2, note the different vertical axis scales) illustrates the effect of drainage regime for the laboratory floor tests, with substantial drainage occurring in the Redhill sand compared to the test in the less permeable Oakamoor sand. This is further demonstrated by comparing the response from the tests in Oakamoor sand at $1 \mathrm{~Hz}$ and $10 \mathrm{~Hz}$, where the higher frequency resulted in displacements that were an order of magnitude lower.

The overall response in the centrifuge tests is similar to the pressure chamber tests, with more flexible behaviour on cycling into tension but overall downward permanent displacement as the average applied load is compressive. However, the centrifuge test data show smaller normalised accumulated displacements (Figure 3). The illustration in Figure 3 is not normalised to account for the difference in ambient average stress level (and the resulting effect on stiffness) experienced in the centrifuge model by comparison with laboratory floor tests. Relevance of centrifuge modelling to the prototype is documented in well established scaling laws, e.g. in Garnier et al. (2007).

Figure 4 compares the unloading stiffnesses, normalised as suggested by Kelly et al. (2006a) to unite small scale laboratory and field data. The centrifuge test results indicate some reduction in unloading stiffness as the cyclic amplitudes increase, which is more 
pronounced in the second loading sequence that was performed at a frequency of $0.25 \mathrm{~Hz}$ (model scale), achieving significant excursions into tension. The unloading stiffnesses are consistent with those of other loading histories as will be shown later (Fig. 15). In comparison, the unloading stiffness deduced from testing in the pressure chamber (Kelly et al., 2006b) suggest significantly higher initial stiffness, with a more substantial reduction under the onerous cyclic loading conditions, such that the unloading stiffness in cycles 50 to 60 is similar to that deduced from the centrifuge tests.

\section{Load Transfer and Pore Pressure Response}

Investigation of the total stresses and excess pore pressures beneath the lid, in relation to the applied pressure, provides insight into the load transfer mechanism. This analysis assumes that the total stress and excess pore pressure measured at the lid invert is representative across the lid invert.

The caisson penetration of $\mathrm{z} / \mathrm{L}=1.14$ (centrifuge Test 4-3) before the application of cyclic loading suggests that the sensor is in contact with the underlying sand. Figure 5 shows the time histories for the two centrifuge tests. Interestingly the total stress carried beneath the lid invert at the start of the tests appears to be negligible, implying that the majority of the applied vertical stress is carried by the skirt. This contrasts with the pressure chamber tests (Kelly et al. 2006b), despite the aspect ratio of the caisson used in the pressure chamber tests being $\mathrm{L} / \mathrm{D}=0.64$ in comparison with 0.5 in the centrifuge tests. Hence, under the same conditions the longer skirts would be expected to carry proportionally more load. However, the increase in self-weight stresses over the skirt length is not significant in the pressure chamber tests. The data hence suggest that this leads to differences in load transfer mechanism.

In both centrifuge tests there is evidence of an increase in the transfer of total stress to the lid invert, as the test proceeds, though the majority of the applied stress is carried by the caisson skirt. More stress is transferred to the lid invert in Test 4-3 with $100 \mathrm{cSt}$ pore fluid (Fig. 5a). Also plotted is the average excess pore pressure, taken as the moving average value of the pore pressure over two cycles of load through the test. For Test 4-3 there is negligible accumulation of the pore pressure, implying that drainage occurs through the 
cyclic loading period. For Test 6-6 (Fig. 5b), with high viscosity pore fluid, there is some increase in the average excess pore pressure as the cyclic amplitude increases, which dissipates over the course of the test. There is negligible accumulated excess pore pressure at the end of the test. Figure 6 shows the relationship between the total stress measured at the lid invert and the excess pore pressure for both tests. The initial response in Test 6-6 (Fig. 6b) is (near) undrained, with Test 4-3 (Fig. 6a) showing a more complex partially drained behaviour. The behaviour demonstrates an increase in the effective stress transferred at the lid invert as the test proceeds.

\section{Effect of average stress, cyclic amplitude and drainage}

The effects of average stress, cyclic amplitude and the drainage conditions are interrelated. Tests 4-2 and 6-1 featured the same cyclic loading history (LC5, Table 1), and a compressive average stress of $10 \mathrm{kPa}$ was maintained throughout. Due to the difference in pore fluid viscosity the resulting drainage regime differed and this has a consequential effect on the caisson response. The loading history comprised of four packages of differing cyclic amplitudes, with all cycles entering the tensile region. Both tests are believed to have achieved full lid contact prior to cyclic loading, based on the achieved penetration depths (Table 1). The response over the four cyclic loading packages is shown in Figure 7a. The following points are observed:

- Near zero movement was measured during the first cyclic load packet in both drainage situations, despite the minimum load being tensile over these 1,000 cycles. This is because the tensile load only amounted to between $20 \%$ and $50 \%$ of the estimated drained frictional tensile capacity.

- Cycling to approximately double the drained frictional tensile limit also resulted in insignificant movement of the caisson. Only the large cyclic amplitudes in the $3^{\text {rd }}$ and $4^{\text {th }}$ packets - at factors of more than 5 and 8 times the drained friction tensile capacity - resulted in significant displacements, both temporary (cyclic) displacements and permanent (average) displacements over the cycle.

- The cyclic loading history resulted in settlement and stiffening/densification in every loading packet in the test with the more viscous pore fluid (Test 6-1). In contrast, significant upward displacement under larger tensile loads was measured in Test 4-2, with the less viscous pore fluid. The different effective permeabilities 
of the soil in the two tests therefore had a noticeable effect, highlighting that assessing drainage is a critical element for design of caissons.

\section{Significance of the drainage regime on the load transfer mechanisms}

Figure 7 shows a comparison of measurements of overall applied vertical stress, total stress at the lid invert and excess pore pressure at the lid invert. For both tests any change in total stress applied at the lid invert is carried entirely by the excess pore pressure (Fig. 7c), indicating an undrained response at this location (the slope is 1 and the correlation coefficient is $\sim 1$ ). However, the proportion of the vertical stress, V/A (where V is the vertical load and A the area of the caisson lid), transferred to total stress at the lid invert, whilst similar in compression, is different in tension for the two different tests (Fig. 7b). There is more load transferred to the lid in the test with lower pore fluid viscosity (i.e. higher permeability, allowing for more drainage), indicating a smaller load carried by the skirts in this test. Indeed for this test, at the higher tensile stresses, the change in applied vertical stress is transferred completely into the excess pore pressure at the lid invert. This is further identified when the effective load is plotted against normalised displacement (Fig. 7d), with effective load defined as V/A - u (essentially the load carried by the soil beneath the lid invert). In the test with lower viscosity fluid this shows a hard limit at around $15 \mathrm{kPa}$, coupled with significant upward displacements. For the test with the higher viscosity fluid a more flexible response is shown from around $30 \mathrm{kPa}$, but with no hard limit, perhaps indicating the effects of partial drainage around the skirt. Given that the suction developed at the lid invert will be a function of the caisson upward velocity and soil permeability it follows that the test with less viscous fluid, which also carries more load as lid suctions, will exhibit a more flexible response in tension. The load transfer behaviour in compression is similar for both tests (with significant fraction of the load carried by the skirts) so the test carrying more load in tension across the lid ratchets upwards, despite the average compressive stress, whilst the other test settles under the loading.

The cyclic loading history was repeated for both tests. Figure 8 shows the effect of a stiffening of response on the settlement, with a gradually decreasing rate of settlement, for the test with more viscous pore fluid (Fig. 8b, Test 6-1). Given the same loading time 
323 history, the partially drained response in Test 4-2 leads to upward movement of the 324 caisson by $\Delta \mathrm{z} / \mathrm{L}=0.04$ over the five cyclic sequences (Fig. 8a). As a greater proportion 325 of the tension load is carried by suction in test 4-2 (Fig. 8c), compared to test 6-1 (Fig. 326 8d), the caisson needs to continue to displace upwards in order to sustain the applied 327 loading.

\section{Effect of average stress}

330 A comparison of the response in three tests, with similar cyclic loading histories, applied 331 around different average stresses (Test 6-4 with LC8 and $0 \mathrm{kPa}$ average stress, 6-1 with 332 LC5 and a average stress of $10 \mathrm{kPa}$ and 6-5 with LC9 and $60 \mathrm{kPa}$ average stress) is shown 333 in Figure 9 and Figure 10. All three tests were performed in the sample with the more 334 viscous pore fluid, with near undrained response to one load cycle. These results yielded 335 the following insights:

336 - A $0 \mathrm{kPa}$ average stress cannot be tolerated due to upward caisson movement irrespective of cyclic amplitude. Tests with average tensile stress were abandoned after less than 100 cycles (Tests 5-1 and 5-3) as caisson extraction would have resulted.

- In contrast, a larger compressive average stress (60 kPa, Test 6-5) leads to overall settlement. In this test, during the compression only loading, the skirt appears to carry the change in applied load, with no load transferred to the lid invert. As the cyclic amplitudes increase, the tensile load is carried by the excess pore pressure, with a correspondingly response characterised by lower stiffness, as previously described.

Effect of low amplitude loading with near zero average stress

348 Of special interest for caisson design is the response at low average applied stress and cyclic amplitudes. Figure 11 shows the results from the initial loading sequences for Tests 5-1 and 5-3. The average stress is also indicated. In both cases a very low average stress has been applied, in one instance just below zero and in the other just above. The cyclic amplitudes applied are small, with the applied tensile loadings comparable, at most, to the drained frictional capacity. In both cases the caisson moves upwards, out of the soil, with no limiting behaviour being reached for the cycles applied. Clearly this type of 
355 loading, and behaviour, must be avoided in design. In each case this loading sequence was stopped during the test, and another less onerous loading applied.

The evolution of stiffness in compression and tension during this initial loading is shown in Figure 12 for selected load cycles. The stiffness in compression reduced to approximately $63 \%$ of its initial value after $\mathrm{N}=28$ cycles in Test $5-3$ and $55 \%$ in Test 5 1 ( $42 \%$ after $\mathrm{N}=82$ cycles). The stiffness in tension also reduced, although the evolution was less severe, with $74 \%$ and $63 \%$ of the initial value after $\mathrm{N}=28$ and 82 cycles, respectively, in Test $5-1$. The stiffness in tension was between 5 and $13 \%$ of the stiffness in compression in Test 5-3, but remained at approximately $40 \%$ in Test 5-1.

\section{Influence of compressive load cycles on response in tension}

367 For Tests 4-2 and 6-1 the cyclic loading amplitude was applied symmetrically about the average stress. Tests 5-2 and 6-2 explore the influence of compressive load cycles on the response in tension. In these tests the caissons were subjected to a cyclic loading sequence with a small but reducing compressive average stress, constant load maxima in compression but increasing minimum loads in tension ('Hansteen type', LC10, Table 1).

The test results, shown in Figure 13, demonstrate that, without any compensating loading into compression, cyclic loading with an average stress slightly in compression and minimum loads in tension result in net upward movement of the caisson, irrespective of the drainage regime and the utilisation in tension (ratio of tensile load compared to drained frictional capacity). As the amplitudes into tension increased, which also meant

378 that the average stress reduced with the increase in tension amplitude, so did the rate of 379 upward displacement. Investigation of the lid invert response indicated that in both cases, 380 particularly under larger loadings, most of the tension load was transferred to the excess 381 pore pressure. As the caisson in more viscous fluid can develop the required suctions at 382 lower displacement rates, it follows that the rate of caisson upward movement is smaller by comparison with the caisson in the less viscous fluid. 
386 Test 6-5 also provides information on the caisson response under compressive loading with occasional cycles into tension. Due to the higher compressive average stress, the minimum loading in the first two cyclic load packages remains compressive. The caisson penetrates downwards. In packets 3 the minimum applied load is around the drained frictional tensile limit, whilst in packet 4 it is about a factor of 4 greater than the drained frictional limit. However, as the average stress remains compressive, the caisson

\section{Effects of partial contact of caisson lid invert with soil} penetrates downwards still further, even under both tensile loading packets.

\section{In Test 5-1 suction installation of the caisson achieved a skirt penetration $\mathrm{z} / \mathrm{L}$ of 0.95 . The} application of $\mathrm{N}=82$ cycles of loading around a tensile average stress $(-6 \pm 16 \mathrm{kPa})$ resulted in an upward movement to $\mathrm{z} / \mathrm{L}=0.78$, as shown in Figure $14 \mathrm{a}$, b. Thereafter, cycling loading (LC6, Table 1) with a average compressive stress was applied, entirely in compression for the first two packets, re-penetrating the caisson to $\mathrm{z} / \mathrm{L}=0.81$. Further cycling in tension, to approximately 30 to $50 \%$ of the drained frictional capacity resulted in additional upward displacement of $\Delta \mathrm{z} / \mathrm{L}=0.07$ in the third packet, even though similar utilisation of the frictional capacity would result in very little damage with full(er) embedment, as shown before (also for tests performed in samples saturated with $100 \mathrm{cSt}$ pore fluid).

The skirt penetration achieved in Test 5-3 was $\mathrm{z} / \mathrm{L}=0.87$ prior to cyclic loading. Cyclic loading of only $\pm 6 \mathrm{kPa}$ applied around $0 \mathrm{kPa}$ average stress (pore fluid viscosity $100 \mathrm{cSt}$ ) resulted in upward movement after $\mathrm{N}=28$ cycles, which is comparable to that measured in Test 6-4 (660 cSt pore fluid, $0 \pm 8 \mathrm{kPa}$ in the first packet) after approximately 250 cycles. The test was therefore stopped in favour of LC7 (Table 1). At this point the skirt penetration was $\mathrm{z} / \mathrm{L}=0.86$. The applied loading history $\mathrm{LC} 7$ with cycling to $-10 \mathrm{kPa}$ (comparable to the drained frictional tensile capacity) led to settlement due to the average stress of $18 \mathrm{kPa}$ (Figs. 14c, d), compared to the significant upward caisson movement measured in Test 5-1 under only 30\% utilisation of the frictional limit. This is similar to the behaviour observed in Test 4-2 (also in samples saturated with $100 \mathrm{cSt}$ pore fluid), which commenced at full skirt penetration. However, at higher utilisation (in packets 2 
417 and 3), upward displacement also occurred in Test 5-3. In Test 4-2, upward movement of

418 the caisson commenced with the application of the $2^{\text {nd }}$ cyclic packet.

419

420 Stiffness of response

421 While the accumulation of foundation displacement is clearly important to the overall 422 serviceability of the OWT, the stiffness of the system is critical, with the blade and rotor 423 eigenfrequencies leaving only a small range suitable for design. For jacket structures the 424 caisson vertical stiffness can be an important contributor to both natural frequency 425 calculations and also fatigue design. Figure 15 shows the secant unloading stiffness, 426 which is relevant for the elastic range considered in dynamic analyses, for a number of 427 the tests completed, normalised as suggested by Kelly et al. (2006a) to permit comparison 428 with other published datasets. The test with $0 \mathrm{kPa}$ average stress (Test 6-4) had the lowest 429 unloading stiffness. By contrast, the test with the highest average compressive stress 430 (60 kPa, Test 6-5) had the highest unloading stiffness, as expected. The effect of the 431 drainage regime on the unloading stiffness is apparent when comparing Test 6-1 (more 432 viscous fluid) and 4-2 (less viscous fluid). (Note that the apparent noise is due to inferring 433 the unloading stiffness from very small changes in displacement.) The ratio of stiffness 434 between 6-5 and 6-1 is approximately in proportion to the square root of the ratio of the 435 average stress levels, assuming a representative stress level at the base of the skirts. 436

437 The results presented in Figure 15 highlight the complexity of selecting a single stiffness 438 that can be used in a structural analysis, to represent all elements of the foundation 439 response, for the 25 year design life of the OWT. This is an area where further work is 440 important.

\section{CONCLUDING REMARKS}

445 This paper has presented a comprehensive set of centrifuge test results that explore the 446 cyclic behaviour of suction caissons in dense sand, particularly the effect of tensile 447 loading on the displacement response. The results add to the database of information that 448 already exists and further highlights that the behaviour under cyclic tensile loading is 
449 rather complex. In particular, the interaction of average stress, cyclic amplitude, cyclic

450 period, drainage and load history must be properly accounted for before cyclic tensile

451 loading could be rationally considered in design, with any real confidence. The results have identified that:

- Purely compressive loading sequences lead to settlement, as expected.

- Cycling under sufficiently compressive average loads leads to settlement of the caisson, even if tensile loads are applied during the cycling. This reinforces the conclusions of previous work.

- Zero or tensile average stress is not tolerated, resulting in significant and ongoing upward displacement of the caisson, even when the applied loads appear to be within the drained frictional tensile capacity.

- The measurements obtained in this series of tests suggest significant differences in the load sharing between caisson skirt and lid, depending on the drainage characteristics. The response to the stresses carried at the lid invert was shown to be undrained. However, for the tests completed there was minimal, if any, accumulation of pore pressure as measured at the lid invert. Rather, the excess pore pressure simply cycled with the applied load.

- The results for the two different pore fluids were differentiated based on the rate of development of suctions at the lid invert with displacement. In both cases an asymmetric load displacement response was observed under larger tensile loading, with a more flexible response observed for the less viscous fluid. Assessment of the likely drainage conditions is clearly an important element for design of caissons.

- The stiffness of the caisson response increased with the average applied load. In all cases the caisson load displacement response becomes less stiff and asymmetric with larger applied tensile loads. This makes selecting a representative stiffness rather more complex. Further work is therefore required to properly understand the relationship between average load, cyclic amplitude, drainage, load history, displacement response, as well as the mobilisation of 
480 The load path for each caisson in a jacket founded OWT will depend on the direction of 481 loading from the environmental conditions (wind, wave and current) as well as the self482 weight and footprint of the jacket. The stiffness response of each individual foundation, 483 and of the structure, will also affect the load distribution between the individual caissons. 484 As the environmental loading (principally the wind) directions change, then the loading 485 on each individual foundation could change significantly. Assessing the optimal design 486 of the caissons for a caisson-founded jacket structure is an iterative and highly complex 487 operation. If an in-service limit of tolerable rotation of $0.25^{\circ}$ is adopted, (in addition to $4880.25^{\circ}$ during installation), then the allowable differential settlement of the caissons is $4890.0044 \mathrm{~S}$, where $\mathrm{S}$ is the centre to centre caisson spacing. Assuming $\mathrm{S}=25 \mathrm{~m}$ and caisson 490 dimensions $\mathrm{D}=8 \mathrm{~m}$ and $\mathrm{L}=4 \mathrm{~m}$, this is equivalent to $\Delta \mathrm{z} / \mathrm{L}=0.027$ (or $\Delta \mathrm{z} / \mathrm{D}=0.014$ ). 491 Comparison of this threshold with the results from the centrifuge tests reported in this 492 paper indicates how the different loading scenarios might be assessed for design, but 493 noting of course that different caisson dimensions will lead to different behaviours for the 494 same applied loads.

496 The results presented in this paper form an important contribution to the broader aim of 497 developing a rational design method for caissons under cyclic loading. The findings have 498 highlighted the importance of measurement of the in-situ permeability in sandy seabeds 499 and the determination of representative loading conditions over the design lifetime for 500 individual caissons. Only by integrating these different elements could an acceptable 501 design method for cyclic loading be developed that accounts for excursions into tension. 502

\section{ACKNOWLEDGEMENTS}

504 This work forms part of the activities of the Centre for Offshore Foundation Systems 505 (COFS), currently supported as a node of the ARC Centre of Excellence for Geotechnical 506 Science and Engineering and as a Centre of Excellence by the Lloyd's Register 507 Foundation. Lloyd's Register Foundation invests in science, engineering and technology 508 for public benefit, worldwide. This support is gratefully acknowledged. 509

\section{REFERENCES}


511 Bienen, B., Klinkvort, R.T., O’Loughlin, C., Zhu, F., Byrne, B.W. (2017). Suction

512

513

514

515

516

517

518

519

520

521

522

523

524

525

526

527

528

529

530

531

532

533

534

535

536

537

538

539

540

541

caissons in dense sand: Part 1 -installation, limiting capacity and drainage. Géotechnique, submitted.

Byrne, B.W. (2000). Investigations of suction caissons in dense sand. DPhil Thesis, Department of Engineering Science, The University of Oxford, UK.

Byrne, B.W., Houlsby, G.T. (2002). Experimental investigations of the response of suction caissons to transient vertical loading. Journal of Geotechnical Engineering (ASCE), Vol. 128, No 11, pp. 926-939.

Byrne, B.W., Houlsby, G.T. (2004). Experimental investigations of the response of suction caissons to transient combined loading. Journal of Geotechnical and Geoenvironmental Engineering (ASCE), Vol. 130, No 3, pp 240-253.

Garnier, J., Gaudin, C. , Springman, S.M., Culligan, P.J., Goodings, D., König, D., Kutter, B., Phillips, R., Randolph, M.F., Thorel, L. (2007). Catalogue of scaling laws and similitude questions in centrifuge modelling. International Journal of Physical Modelling in Geotechnics, Vol. 7, No. 3, pp. 1-24.

Hansteen, O.E. (1981). Equivalent geotechnical design storm. NGI internal report 4000716.

Henke, S. (2013). Untersuchungen zur Pfropfenbildung infolge der Installation offener Profile in granularen Böden. Habilitation Thesis, Technical University of HamburgHarburg, Germany.

Houlsby, G.T. (2016). Interactions in offshore foundation design. Géotechnique, Vol. 66, No. 10, pp. 791-825.

Houlsby, G.T., Kelly, R.B., Byrne, B.W. (2005). The Tensile Capacity of Suction Caissons in Sand under Rapid Loading. Proc. International Symposium on Frontiers in Offshore Geotechnics (ISFOG), pp 405-410.

Houlsby, G.T., Kelly, R.B., Huxtable, J., Byrne, B.W. (2006). Field trials of suction caissons in sand for offshore wind turbine foundations. Géotechnique, Vol. 56, No. 1, pp 3-10.

Kelly, R.B., Houlsby, G.T., Byrne, B.W. (2006a). A comparison of field and laboratory tests of caisson foundations in sand and clay. Géotechnique, Vol. 56, No. 9, pp. 617626. 
542 Kelly, R.B., Houlsby, G.T., Byrne, B.W. (2006b). Transient vertical loading of model

543 suction caissons in a pressure chamber. Géotechnique, Vol. 56, No. 10, pp. 665-675.

544 Senders, M. (2008). Suction caissons in sand as tripod foundations for offshore wind 545 turbines. PhD Thesis, University of Western Australia, Australia.

546 Tran, M.N. (2005). Installation of suction caissons in dense sand and the influence of silt 547 and cemented layers. PhD Thesis, University of Sydney, Australia. 


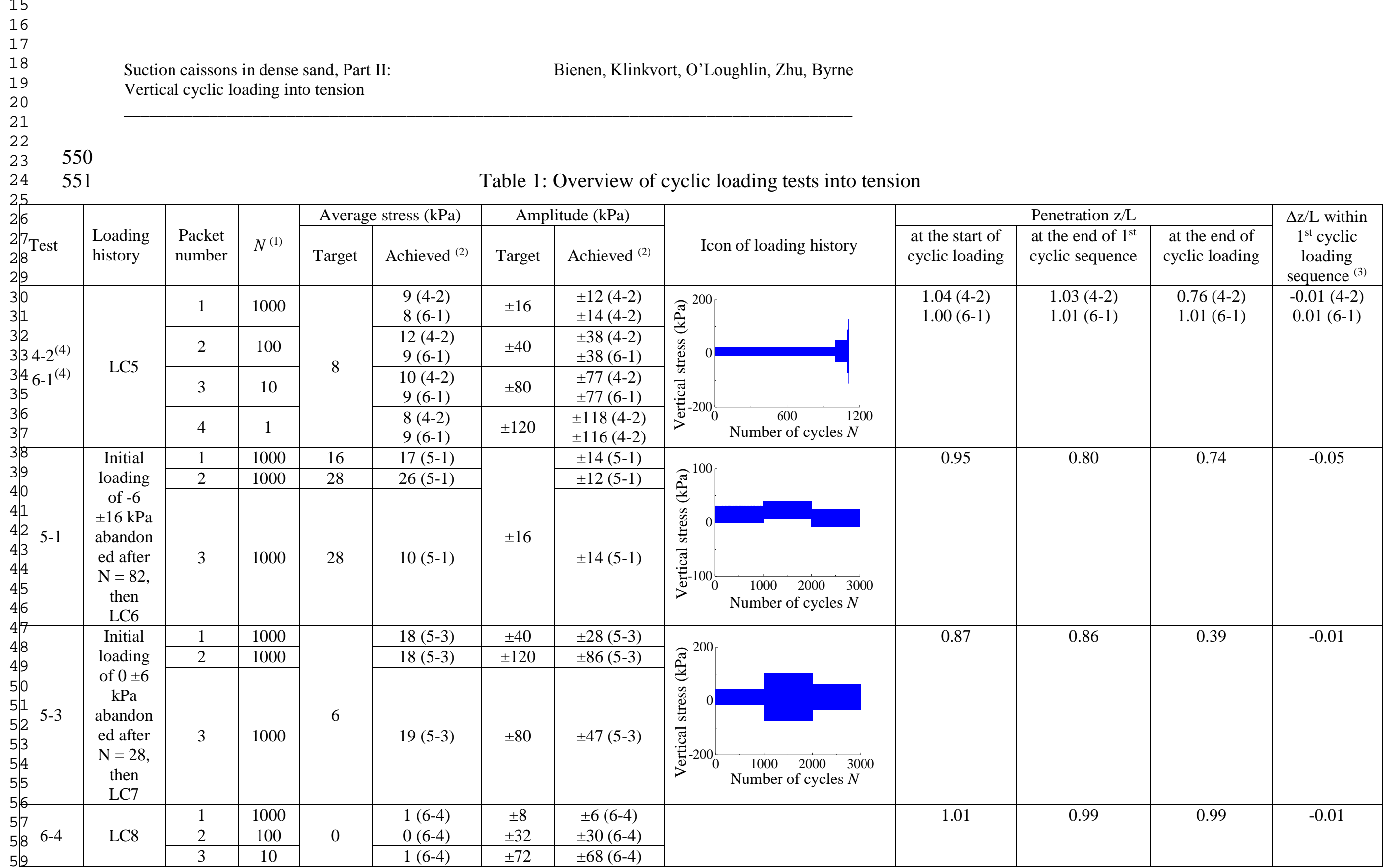




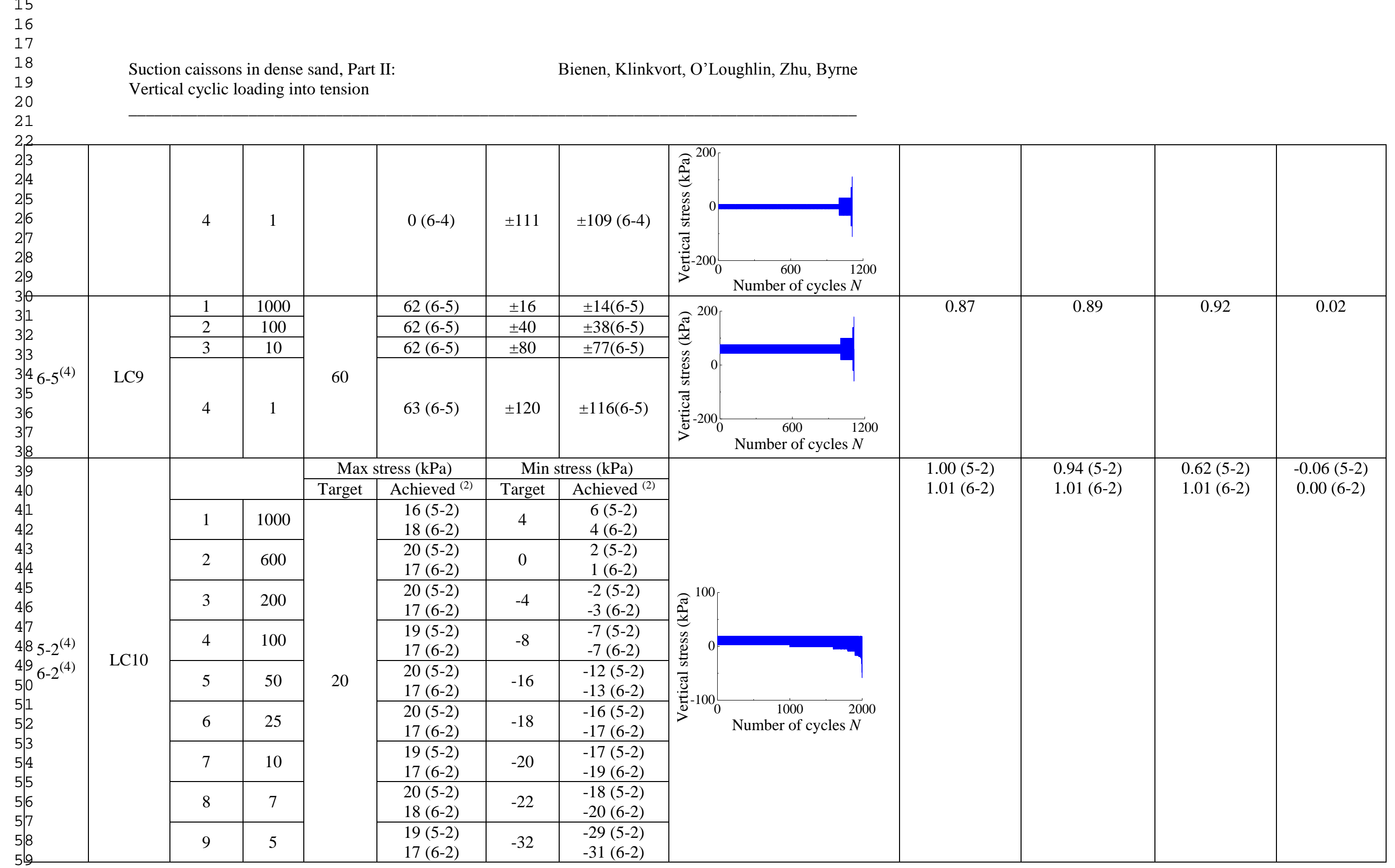

60 


\begin{tabular}{|c|c|c|c|c|c|}
\hline $\begin{array}{l}23 \\
24\end{array}$ & 10 & 2 & $\begin{array}{c}19(5-2) \\
17(6-2)\end{array}$ & -48 & $\begin{array}{l}-45(5-2) \\
-47(6-2)\end{array}$ \\
\hline \begin{tabular}{l|l}
2 & 5 \\
26
\end{tabular} & 11 & 1 & $\begin{array}{l}19(5-2) \\
17(6-2)\end{array}$ & -60 & $\begin{array}{l}-55(6-2) \\
-59(6-2)\end{array}$ \\
\hline
\end{tabular}

$26 \quad 552 \quad{ }^{2} 6 \quad N$ is the number of cycles in each packet

$28553 \quad$ (2) Achieved loads are determined based on the $1^{\text {st }}$ series of loading if the loading sequence was repeated.

$29 \quad 554 \quad$ (3) Settlement is positive and heave is negative.

$30 \quad 555 \quad$ (4) Loading sequence repeated, see Table 1 of companion paper (Bienen et al, 2017). 
560 Table 2: Cyclic loading history applied in Tests 4-3, 6-6 and Kelly et al. (2006b)

\begin{tabular}{|c|c|c|c|c|c|}
\hline \multirow{2}{*}{$\begin{array}{l}\text { Packet } \\
\text { number } \\
(1)\end{array}$} & \multicolumn{2}{|c|}{ Average stress $(\mathrm{kPa})$} & \multicolumn{2}{|r|}{ Amplitude $(\mathrm{kPa})$} & \multirow{2}{*}{ Icon of loading history } \\
\hline & Target & Achieved & Target & Achieved & \\
\hline 1 & \multirow{8}{*}{569} & $\begin{array}{c}566^{(2)}, 567^{(3)}(4-3) \\
567^{(2)}, 567^{(3)}(6-6) \\
536\left(6^{(4)}\right) \\
556\left(14^{(4)}\right) \\
608\left(21^{(4)}\right)\end{array}$ & \pm 81 & $\begin{array}{c} \pm 79^{(2)}, \pm 79^{(3)}(4-3) \\
\pm 79^{(2)}, \pm 79^{(3)}(4-3) \\
\quad \pm 59\left(6^{(4)}\right) \\
\pm 89\left(14^{(4)}\right) \\
\pm 46\left(21^{(4)}\right)\end{array}$ & \multirow{8}{*}{ 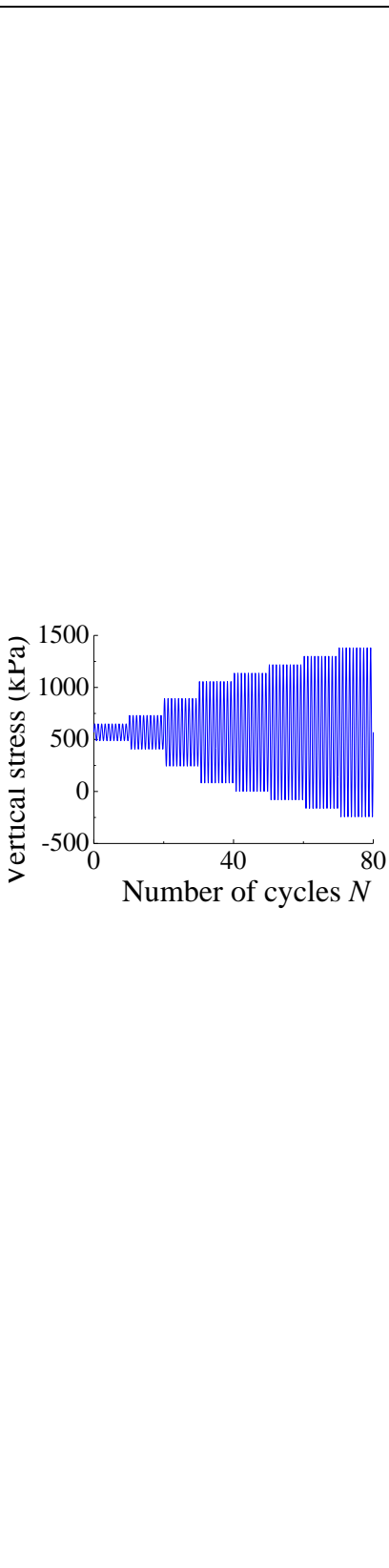 } \\
\hline 2 & & $\begin{array}{c}566^{(2)}, 566^{(3)}(4-3) \\
566^{(2)}, 567^{(3)}(6-6) \\
529\left(6^{(4)}\right) \\
563\left(14^{(4)}\right) \\
603\left(21^{(4)}\right)\end{array}$ & \pm 162 & $\begin{array}{l} \pm 159^{(2)}, \pm 160^{(3)}(4-3) \\
\pm 160^{(2)}, \pm 160^{(3)}(6-6) \\
\quad \pm 136\left(6^{(4)}\right) \\
\quad \pm 179\left(14^{(4)}\right) \\
\pm 134\left(21^{(4)}\right)\end{array}$ & \\
\hline 3 & & $\begin{array}{c}564^{(2)}, 564^{(3)}(4-3) \\
564^{(2)}, 562^{(3)}(6-6) \\
524\left(6^{(4)}\right) \\
580\left(14^{(4)}\right) \\
594\left(21^{(4)}\right)\end{array}$ & \pm 325 & $\begin{array}{l} \pm 322^{(2)}, \pm 323^{(3}(4-3) \\
\pm 322^{(2)}, \pm 324^{(3)}(6-6) \\
\quad \pm 293\left(6^{(4)}\right) \\
\pm 357\left(14^{(4)}\right) \\
\pm 297\left(21^{(4)}\right)\end{array}$ & \\
\hline 4 & & $\begin{array}{c}565^{(2)}, 566^{(3)}(4-3) \\
564^{(2)}, 564^{(3)}(6-6) \\
540\left(6^{(4)}\right) \\
624\left(14^{(4)}\right) \\
613\left(21^{(4)}\right)\end{array}$ & \pm 487 & $\begin{array}{l} \pm 481^{(2)}, \pm 482^{(3)}(4-3) \\
\pm 479^{(2)}, \pm 484^{(3)}(6-6) \\
\quad \pm 441\left(6^{(4)}\right) \\
\pm 543\left(14^{(4)}\right) \\
\pm 454\left(21^{(4)}\right)\end{array}$ & \\
\hline 5 & & $\begin{array}{c}553^{(2)}, 565^{(3)}(4-3) \\
536^{(2)}, 563^{(3)}(6-6) \\
553\left(6^{(4)}\right) \\
680\left(14^{(4)}\right) \\
636\left(21^{(4)}\right)\end{array}$ & \pm 568 & $\begin{array}{c} \pm 533^{(2)}, \pm 563^{(3)}(4-3) \\
\pm 526^{(2)}, \pm 565^{(3)}(6-6) \\
\quad \pm 524\left(6^{(4)}\right) \\
\pm 640\left(14^{(4)}\right) \\
\pm 529\left(21^{(4)}\right)\end{array}$ & \\
\hline 6 & & $\begin{array}{c}540^{(2)}, 561^{(3)}(4-3) \\
529^{(2)}, 560^{(3)}(6-6) \\
608\left(6^{(4)}\right) \\
685\left(14^{(4)}\right) \\
661\left(21^{(4)}\right)\end{array}$ & \pm 650 & $\begin{array}{c} \pm 524^{(2)}, \pm 639^{(3)}(4-3) \\
\pm 509^{(2)}, \pm 640^{(3)}(6-6) \\
\quad \pm 605\left(6^{(4)}\right) \\
\pm 676\left(14^{(4)}\right) \\
\pm 594\left(21^{(4)}\right)\end{array}$ & \\
\hline 7 & & $\begin{array}{l}529^{(2)}, 559^{(3)}(4-3) \\
521^{(2)}, 570^{(3)}(6-6)\end{array}$ & \pm 731 & $\begin{array}{l} \pm 536^{(2)}, \pm 713^{(3)}(4-3) \\
\pm 501^{(2)}, \pm 702^{(3)}(6-6)\end{array}$ & \\
\hline 8 & & $\begin{array}{l}515^{(2)}, 551^{(3)}(4-3) \\
535^{(2)}, 576^{(3)}(6-6)\end{array}$ & \pm 812 & $\begin{array}{l} \pm 540^{(2)}, \pm 749^{(3)}(4-3) \\
\pm 513^{(2)}, \pm 733^{(3)}(6-6)\end{array}$ & \\
\hline
\end{tabular}

$561 \quad{ }^{(1)}$ Each packet contained $N=10$ cycles

$562{ }^{(2)}$ Achieved loads reported for the $1^{\text {st }}$ series of loading $(0.5 \mathrm{~Hz})$

$563{ }^{(3)}$ Achieved loads reported for the $2^{\text {nd }}$ series of loading $(0.25 \mathrm{~Hz})$

$564{ }^{(4)}$ Tests 6, 14 and 21 as reported in Kelly et al. (2006b), only 5 cycles were applied in 565 packet 5 and 6 for tests 14 and 21 
568 Figure 1: Schematic forces experienced by offshore wind turbine, a) suction caisson supported jacket substructure installed, b) OWT fully installed, c) in service.

598 Figure 11: Cyclic loading with low amplitude and low average loads, a) Test 5-1, b)

599 Test 5-3. Plotted on the figure is also the average load, taken as a moving average over

600 two load cycles.

Figure 2: Caisson response under cyclic loading with compressive average load and amplitudes increasing towards tension (Kelly et al. 2006b), a) Redhill 1Hz, b) Oakamoor $1 \mathrm{~Hz}, \mathrm{c})$ and d) Oakamoor $10 \mathrm{~Hz}$. Note the different scale for plot d).

Figure 3: Results from the centrifuge tests, a) Test 4-3, $f=0.5 \mathrm{~Hz}, \mathrm{~b}$ ) Test $4-3, \mathrm{f}=0.25$ $\mathrm{Hz}, \mathrm{c})$ Test 6-6, $\mathrm{f}=0.5 \mathrm{~Hz}, \mathrm{~d})$ Test 6-6, $\mathrm{f}=0.25 \mathrm{~Hz}$.

Figure 4: Unloading stiffness: comparison of centrifuge test results with data from pressure chamber tests.

Figure 5: Time history for centrifuge tests, a) Test 4-3, b) Test 6-6. Note that the scales are different for the vertical stresses and the pore pressures.

Figure 6: Comparison of drainage response at the lid invert, a) Test 4-3, b) Test 6-6.

Figure 7: Effect of drainage on load transfer mechanism in tests with cyclic loading into tension with small compressive average stress, a) applied stress, b) total stress at lid invert, c) drainage at lid invert, d) effective load at lid invert.

Figure 8: Caisson response over five cyclic loading sequences, applied stress, a) Test 42, b) Test 6-1; total stress and excess pore pressure at the lid invert, c) Test 4-2, d) Test 6-1.

Figure 9: Effect of average stress, Tests a) 6-4, b) 6-1 and c) 6-5.

Figure 10: Comparison of tests with same cyclic sequence but different initial conditions.

601 
602 Figure 12: Evolution of stiffness in compression and tension, a) Test 5-1, b) Test 5-3.

603

604 Figure 13: Response to 'Hansteen type' loading, a) Test 5-2, b) Test 6-2.

605

606 Figure 14: Test 5-1 (a, b) and 5-3 (c, d): applied stress (a, c), excess pore pressure at lid 607 invert (b, d). Data shown as first and last cycles of each packet.

608

609 Figure 15: Effect on unloading stiffness of different average loads and drainage 610 conditions.

611 


\begin{tabular}{lll}
612 & \multicolumn{2}{l}{ Notation } \\
613 & A & caisson area \\
614 & D & caisson diameter \\
615 & $D_{\mathrm{r}}$ & relative density \\
616 & $\mathrm{f}$ & cyclic loading frequency \\
617 & $\mathrm{~L}$ & caisson skirt length \\
618 & $\mathrm{~N}$ & number of cycles \\
619 & $\mathrm{~S}$ & centre to centre caisson spacing \\
620 & $\mathrm{t}$ & skirt thickness \\
621 & $\mathrm{~V}$ & vertical load \\
622 & $\mathrm{Z}$ & penetration depth \\
623 & $\Delta \mathrm{u}$ & excess pore pressure \\
624 & $\Delta \mathrm{z}$ & change in vertical displacement \\
625 & $\sigma$ & total stress
\end{tabular}


a)

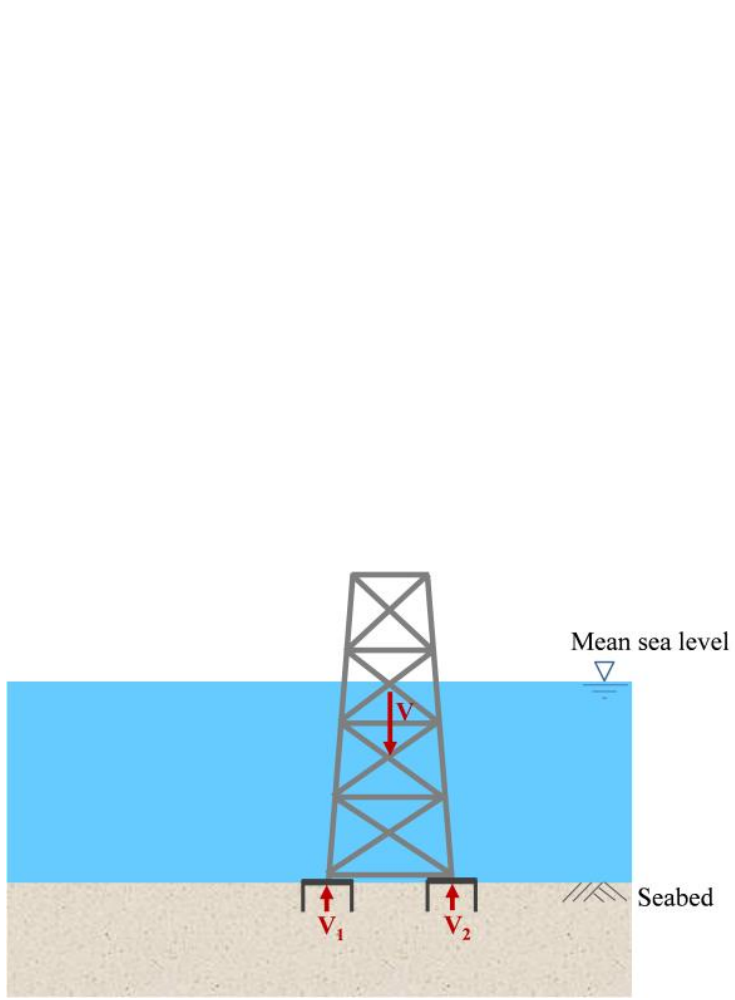

b)

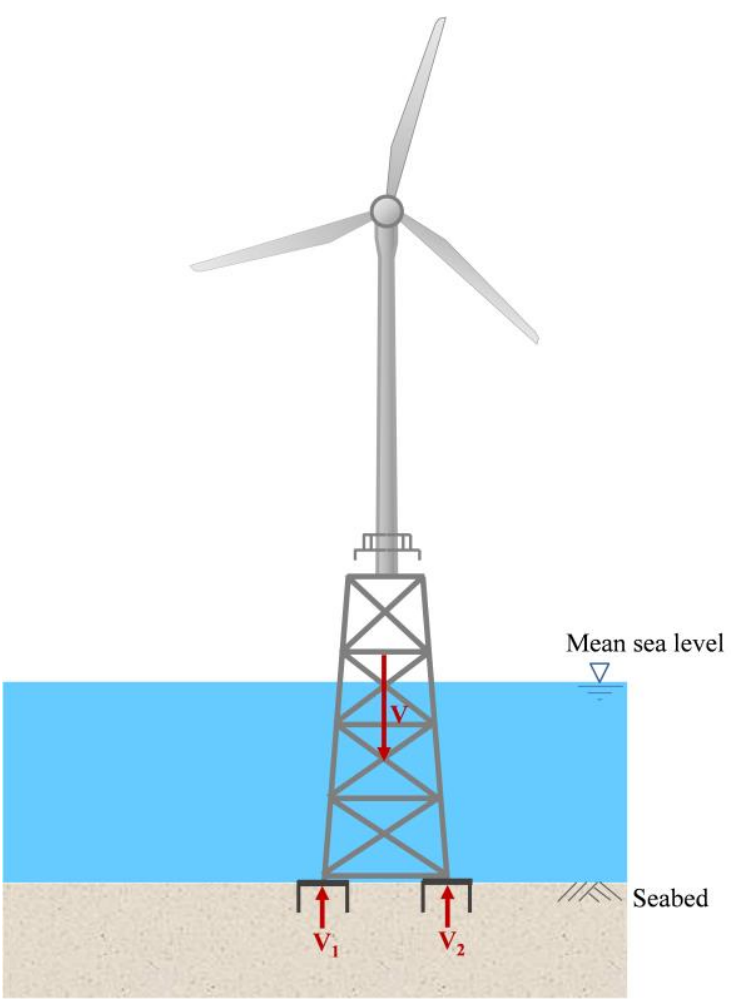

)

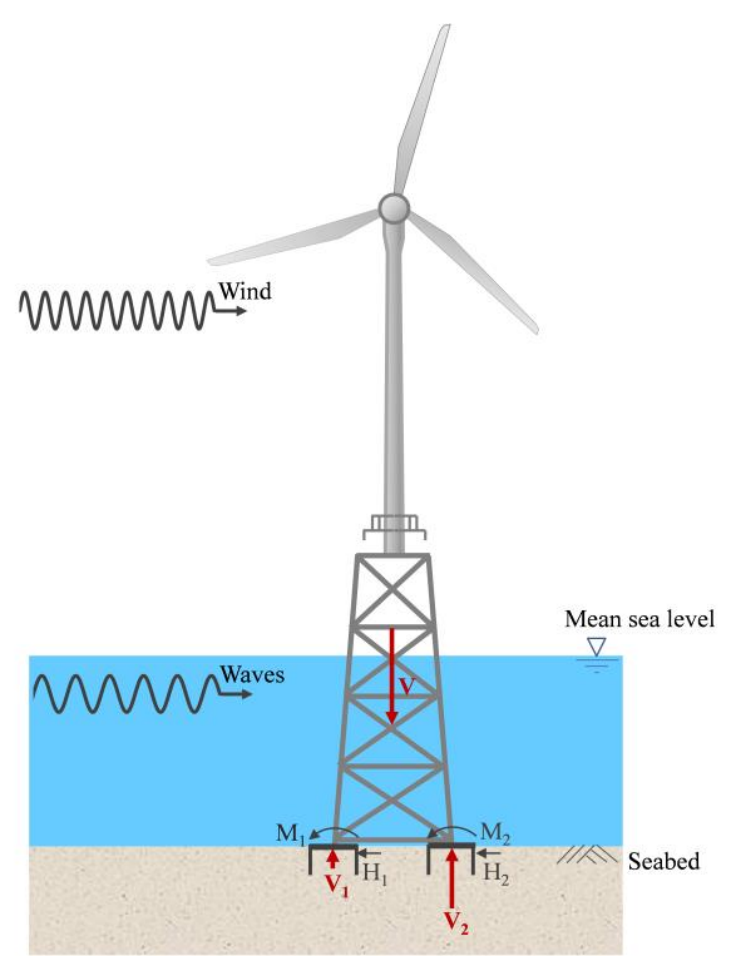

Figure 1: Schematic forces experienced by offshore wind turbine, a) suction caisson supported jacket substructure installed, b) OWT fully installed, c) in service. 
a)

$\mathrm{V} / \mathrm{A}(\mathrm{kPa})$

$-200 \quad 0 \quad 200 \quad 400 \quad 600 \quad 800100012001400$

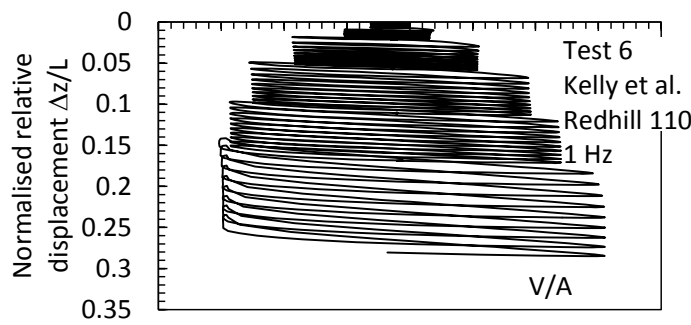

$\Delta \mathrm{u}(\mathrm{kPa})$

$-200 \quad 0 \quad 200400 \quad 600800100012001400$

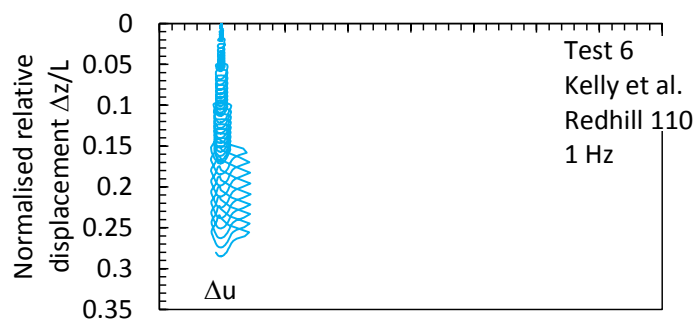

c)

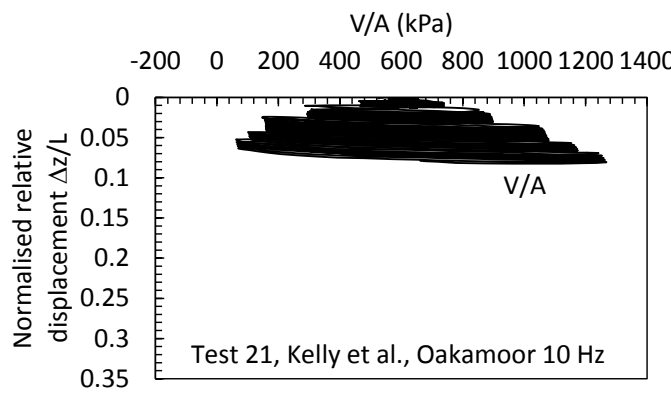

$\Delta \mathrm{u}(\mathrm{kPa})$

$\begin{array}{lllllll}-200 & 0 & 200 & 400 & 600 & 800 & 100012001400\end{array}$

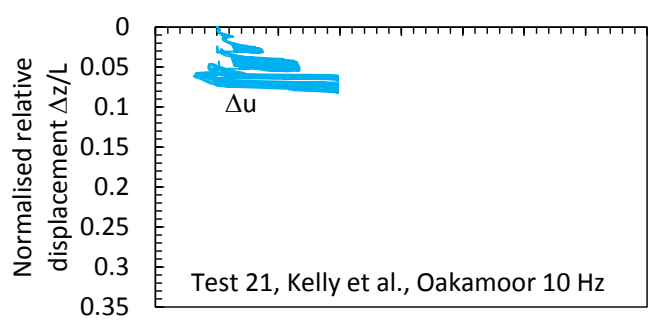

b)

$\mathrm{V} / \mathrm{A}(\mathrm{kPa})$

$-200 \quad 0 \quad 200 \quad 400600 \quad 800100012001400$

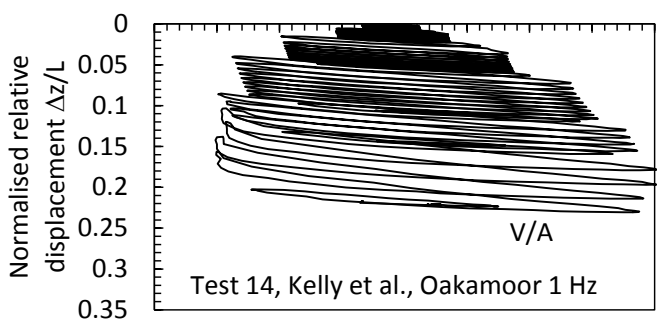

$\Delta \mathrm{u}(\mathrm{kPa})$

$-200 \quad 0 \quad 200 \quad 400600 \quad 800100012001400$

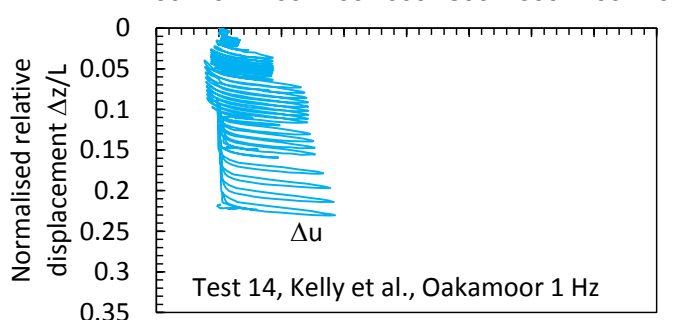

d)

$\mathrm{V} / \mathrm{A}(\mathrm{kPa})$

$\begin{array}{lllllll}-200 & 0 & 200 & 400 \quad 600800100012001400\end{array}$

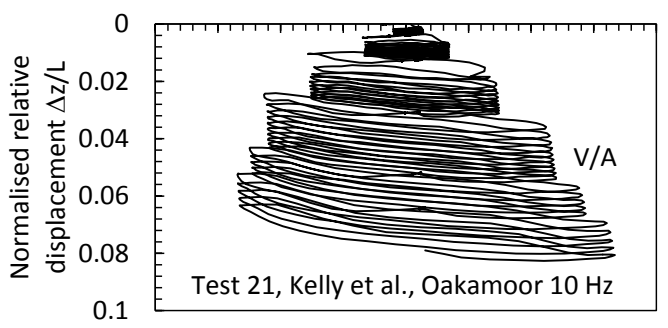

$\Delta \mathrm{u}(\mathrm{kPa})$

$-200 \quad 0 \quad 200400600 \quad 800100012001400$

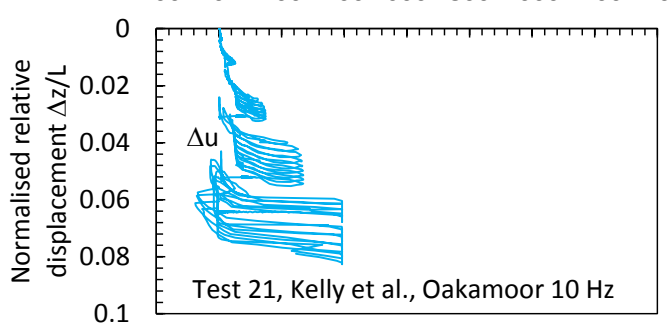

Figure 2: Caisson response under cyclic loading with compressive average load and amplitudes increasing towards tension (Kelly et al. 2006b), a) Redhill $1 \mathrm{~Hz}$, b) Oakamoor $1 \mathrm{~Hz}, \mathrm{c}$ ) and d) Oakamoor $10 \mathrm{~Hz}$. Note the different scale for plot d). 
a)

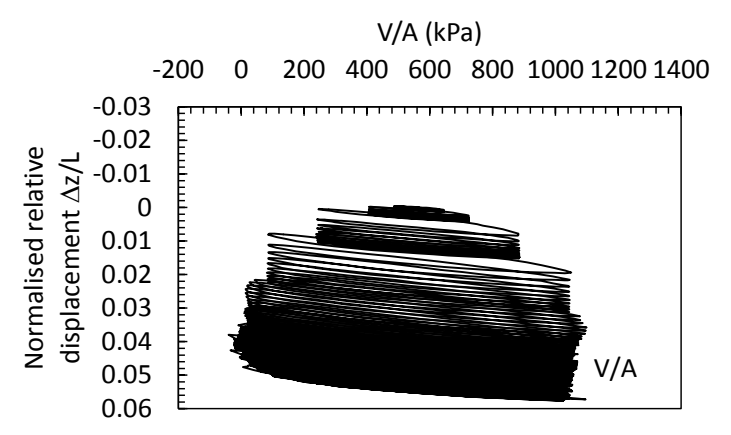

$\sigma, \Delta \mathrm{u}(\mathrm{kPa})$

$\begin{array}{lllllll}-200 & 0 & 200 & 400 & 600 \quad 800 & 1000 & 12001400\end{array}$

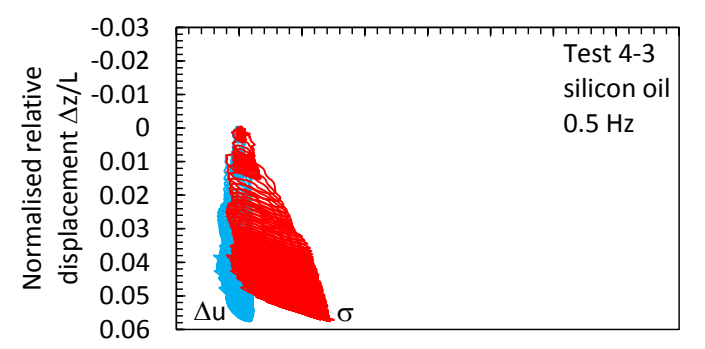

c)

$\mathrm{V} / \mathrm{A}(\mathrm{kPa})$

$-200 \quad 0 \quad 200400600 \quad 800100012001400$

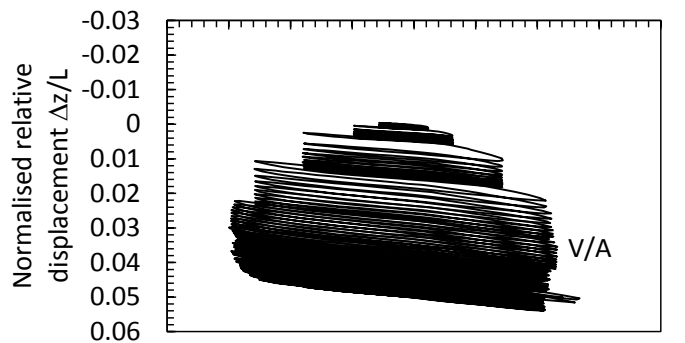

$\sigma, \Delta \mathrm{u}(\mathrm{kPa})$

$-200 \quad 0 \quad 200400600 \quad 800100012001400$

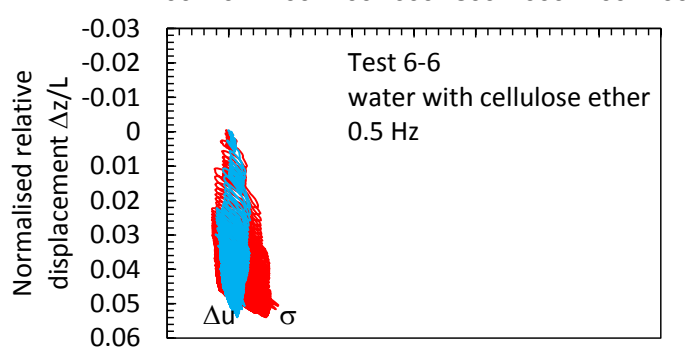

b)

$\mathrm{V} / \mathrm{A}(\mathrm{kPa})$

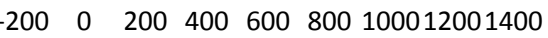

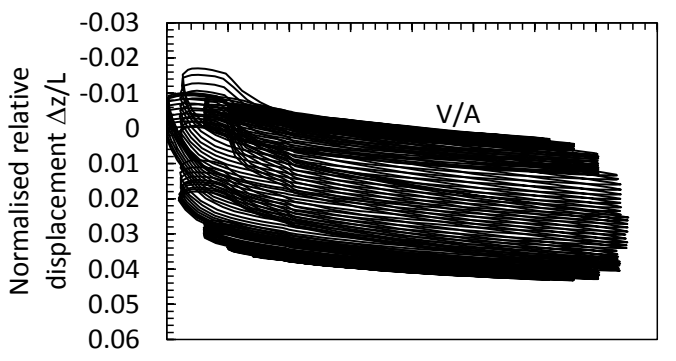

$\sigma, \Delta \mathrm{u}(\mathrm{kPa})$

$-200 \quad 0 \quad 200 \quad 400600800100012001400$

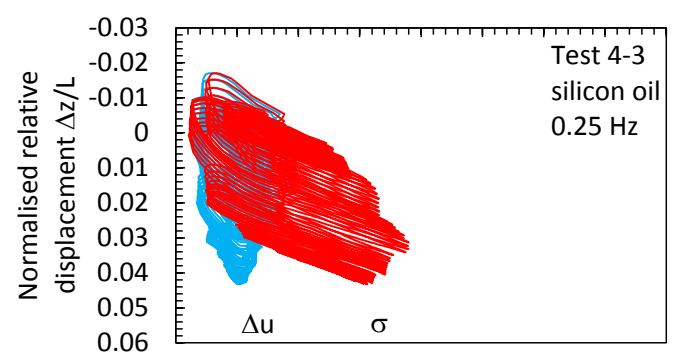

d)

$\mathrm{V} / \mathrm{A}(\mathrm{kPa})$

$-200 \quad 0 \quad 200400600 \quad 800100012001400$

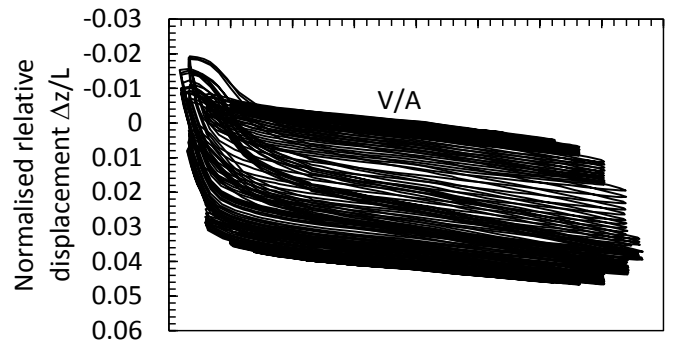

$\sigma, \Delta \mathrm{u}(\mathrm{kPa})$

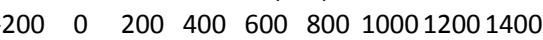

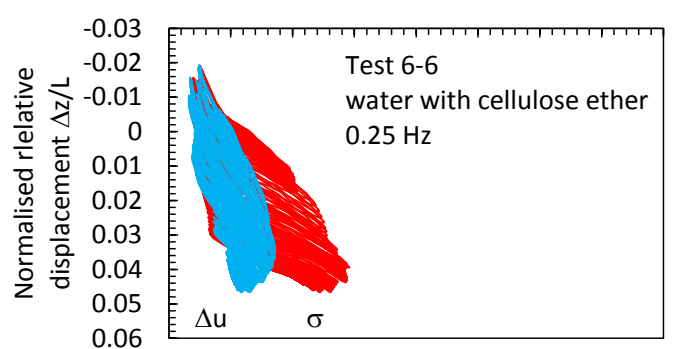

Figure 3: Results from the centrifuge tests, a) Test $4-3, \mathrm{f}=0.5 \mathrm{~Hz}, \mathrm{~b})$ Test $4-3, \mathrm{f}=0.25$ $\mathrm{Hz}, \mathrm{c})$ Test 6-6, $\mathrm{f}=0.5 \mathrm{~Hz}, \mathrm{~d}$ ) Test 6-6, $\mathrm{f}=0.25 \mathrm{~Hz}$. 


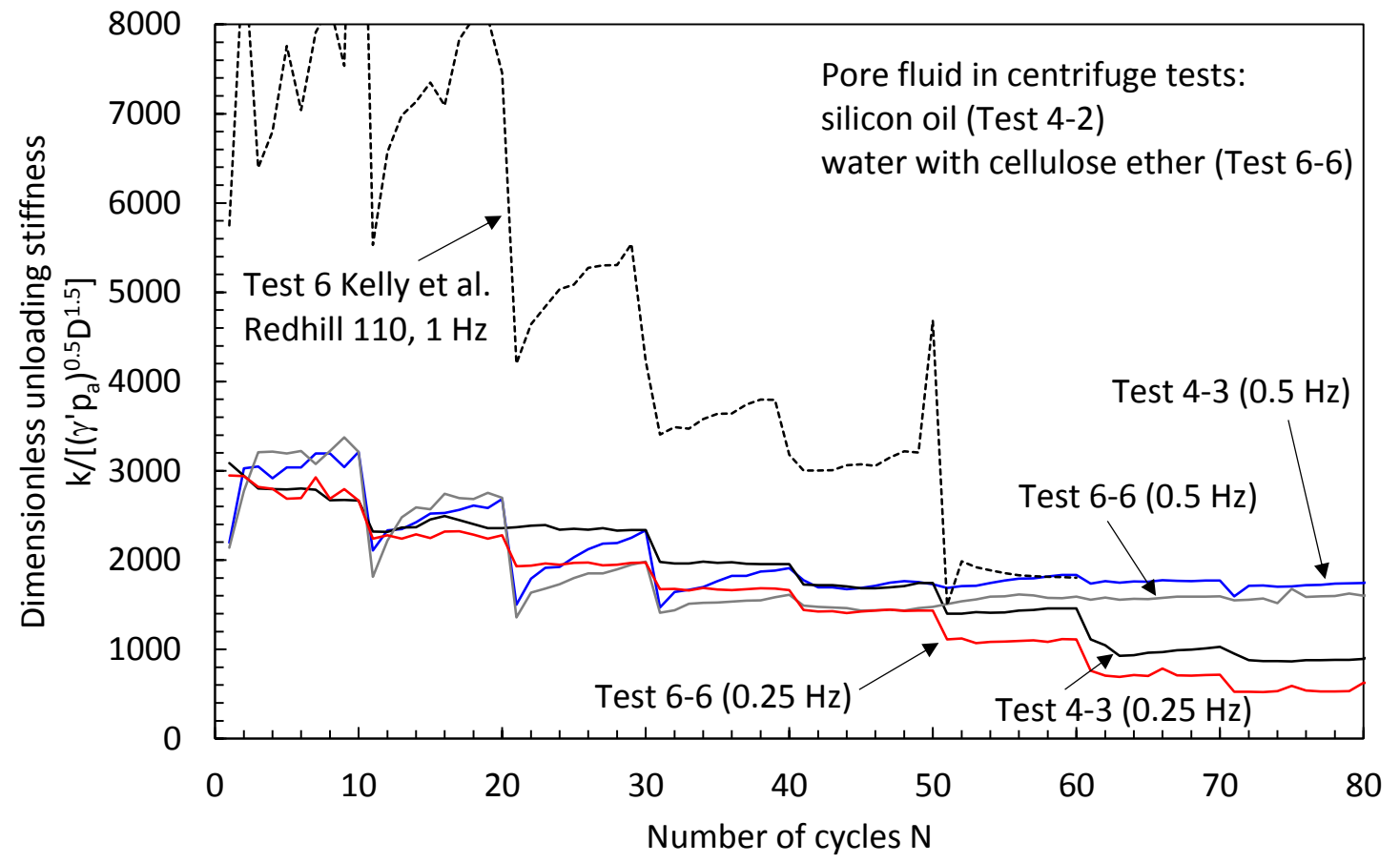

Figure 4: Unloading stiffness: comparison of centrifuge test results with data from pressure chamber tests. 
a)

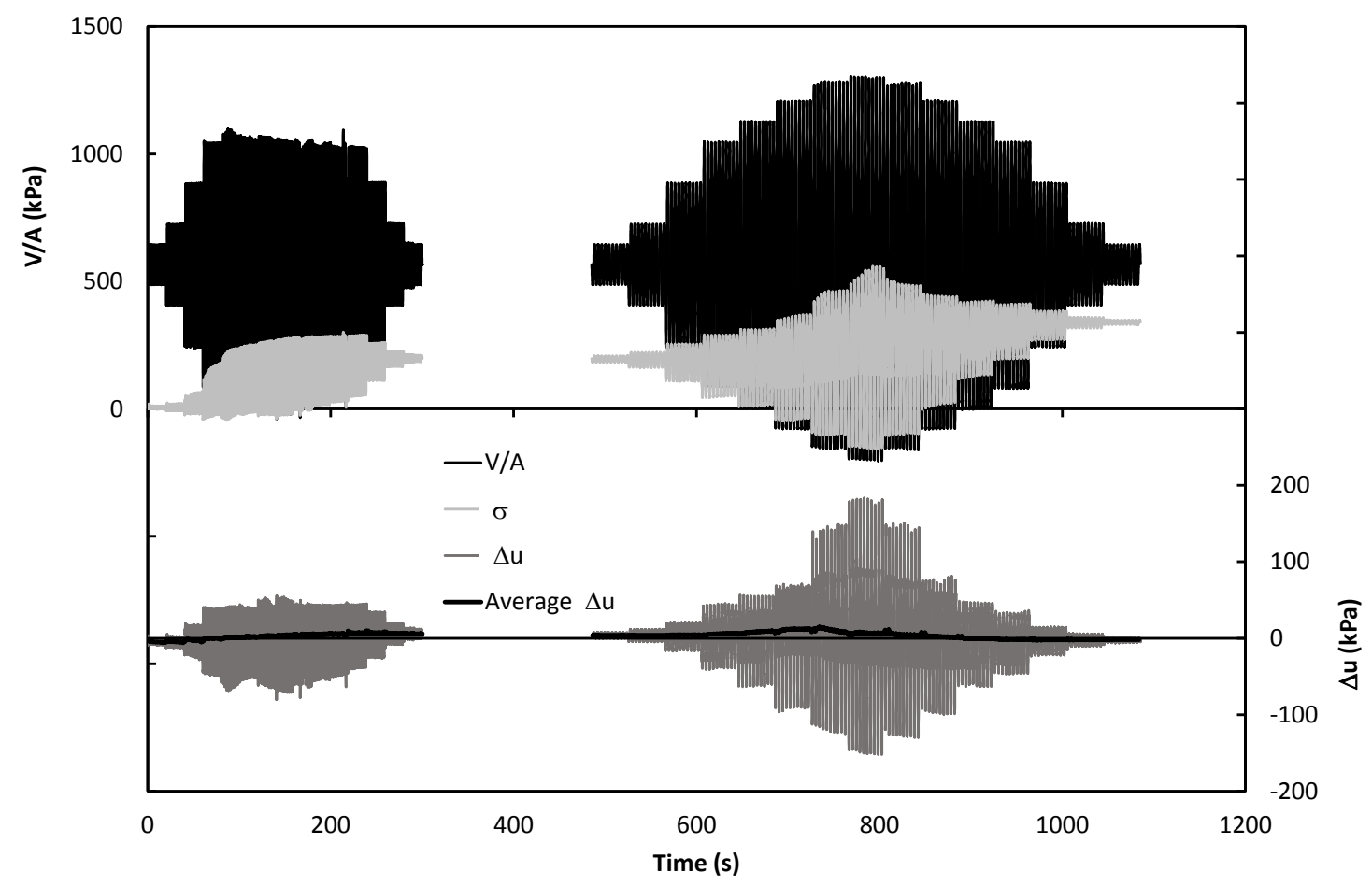

b)

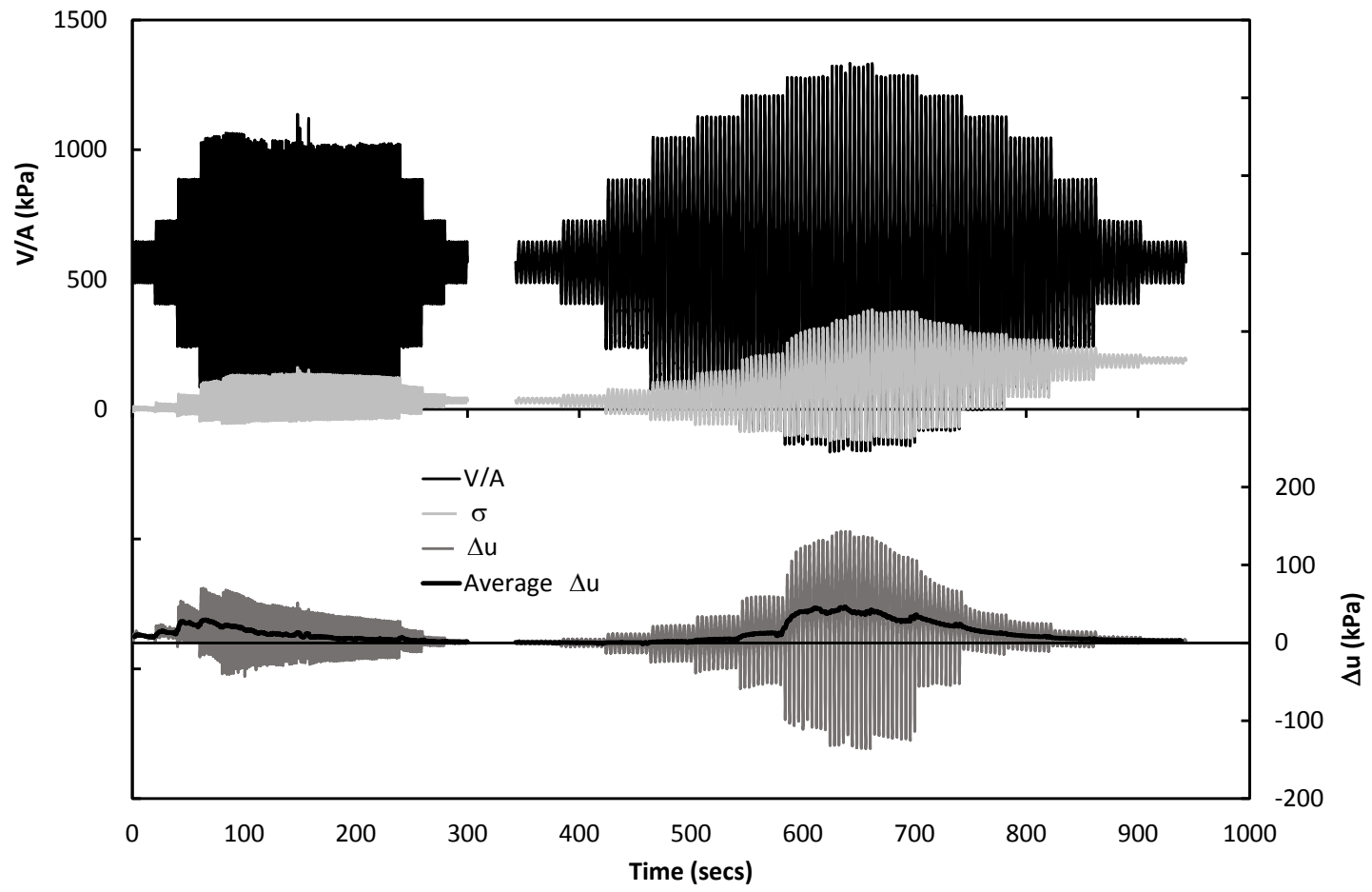

Figure 5: Time history for centrifuge tests, a) Test 4-3, b) Test 6-6. Note that the scales are different for the vertical stresses and the pore pressures. 
a)

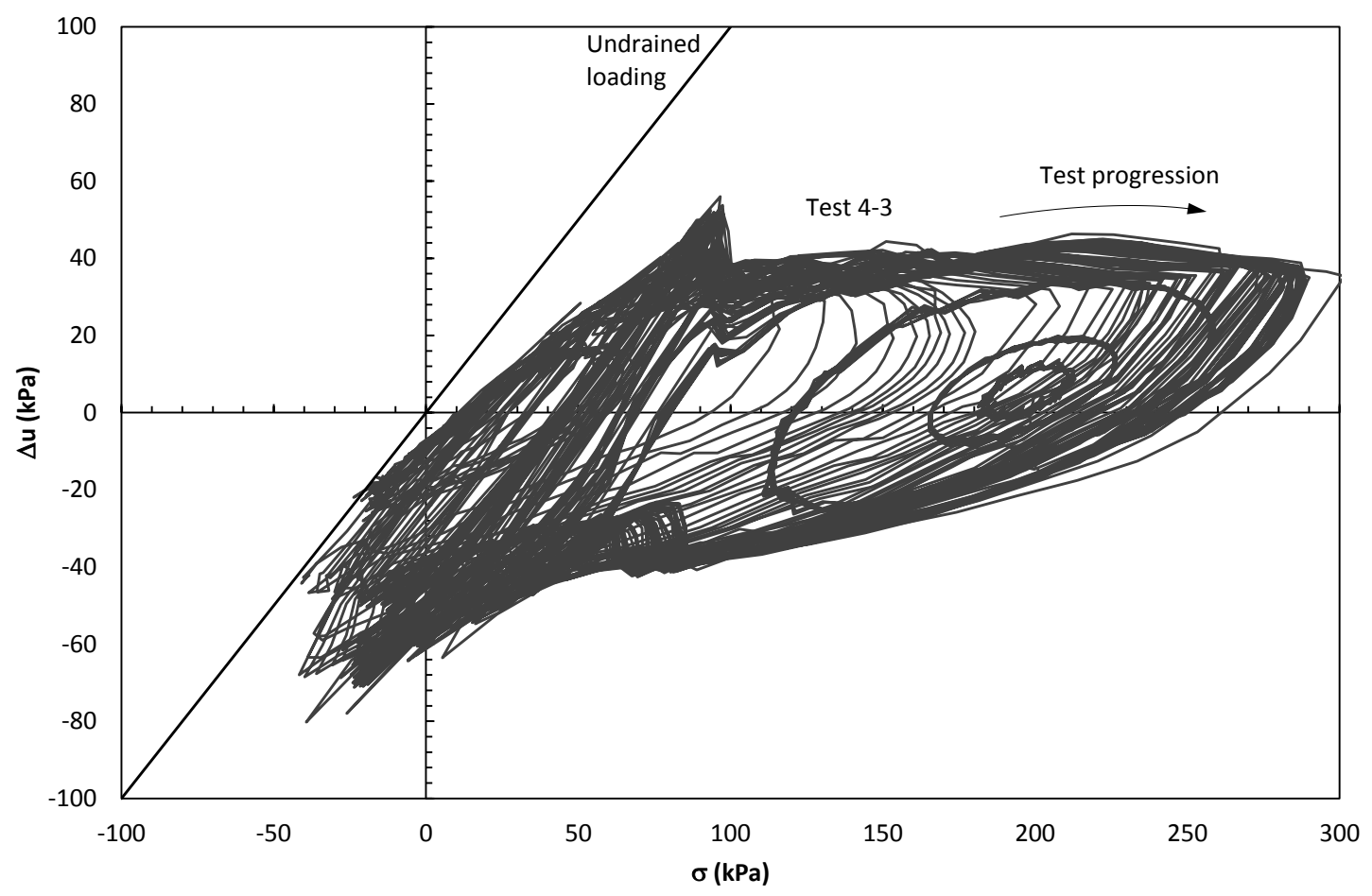

b)

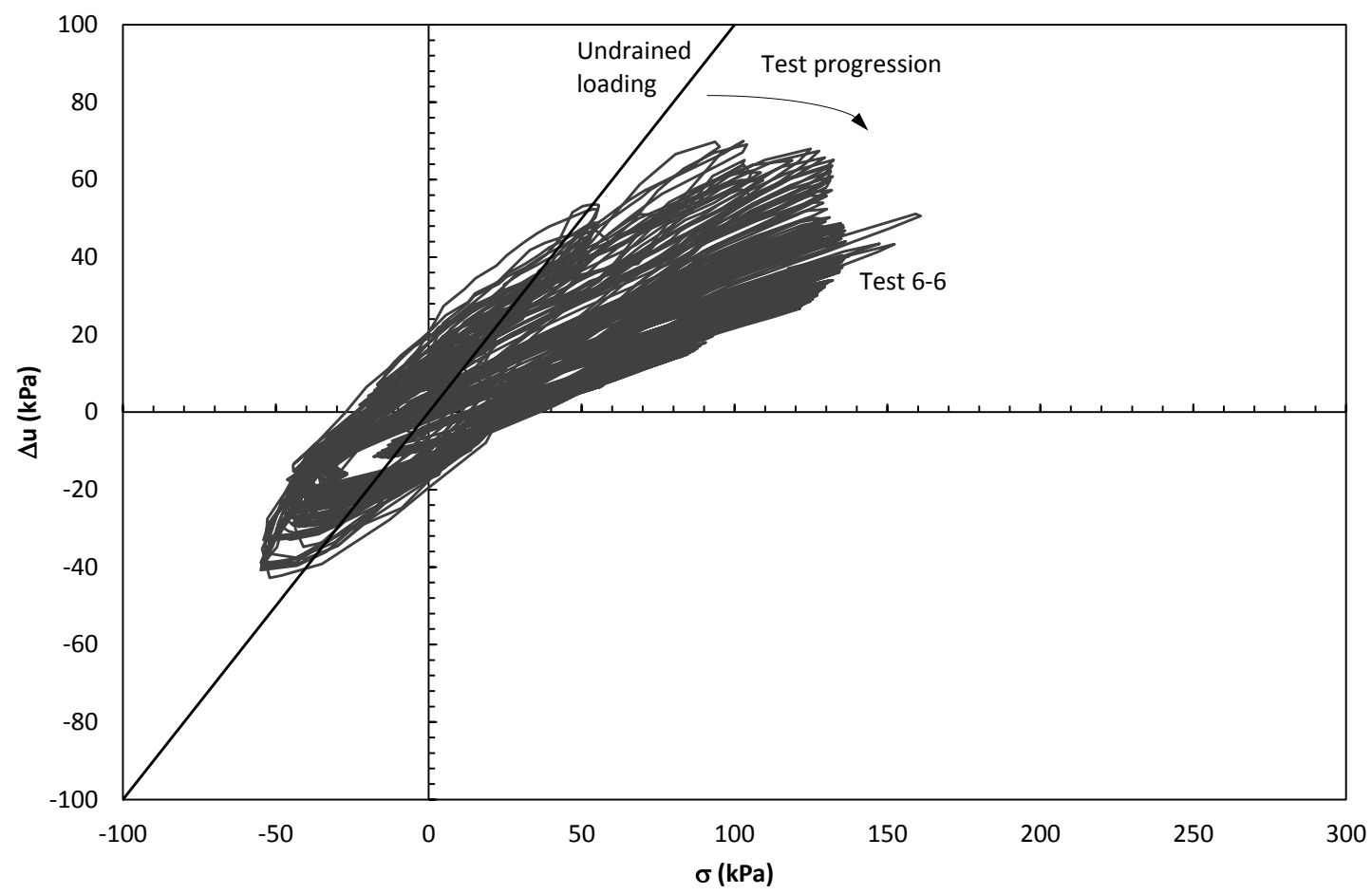

Figure 6: Comparison of drainage response at the lid invert, a) Test 4-3, b) Test 6-6. 
a)

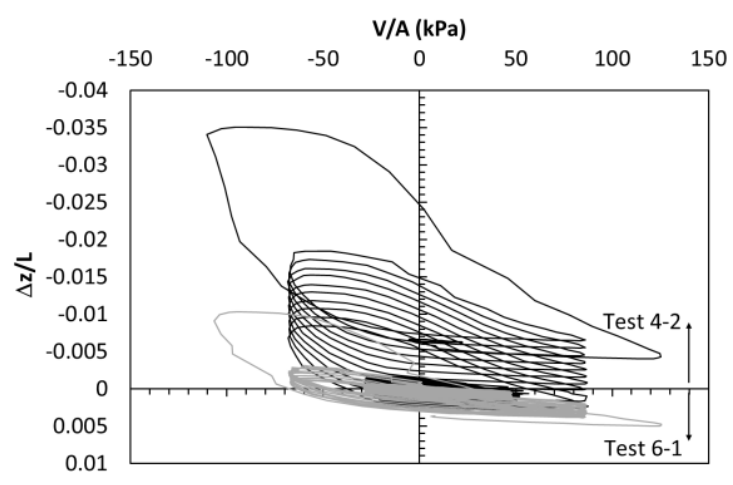

c)

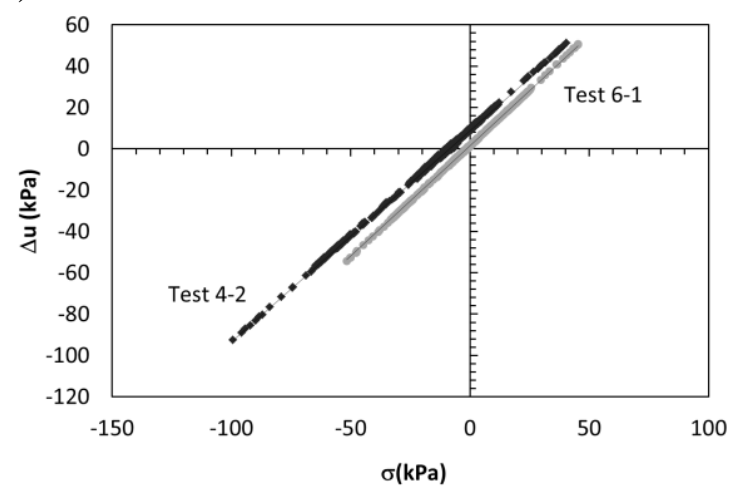

b)

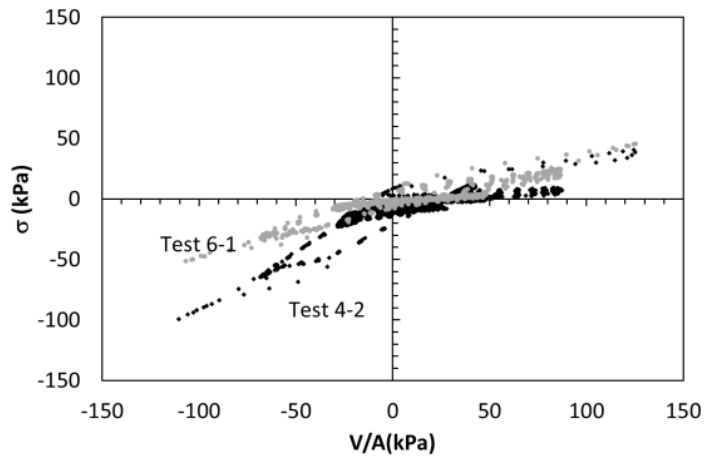

d)

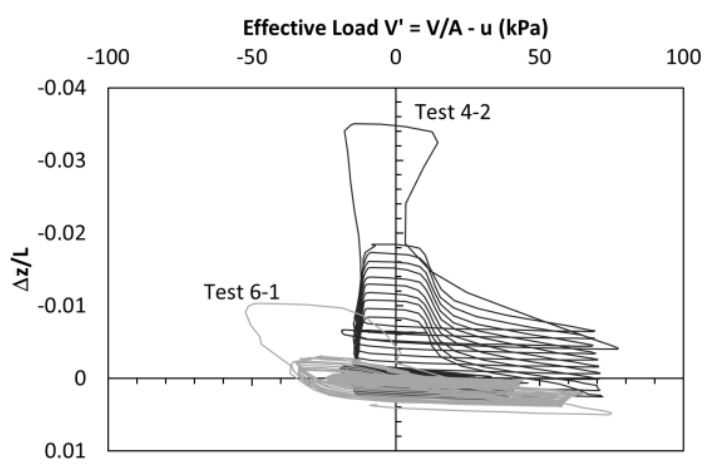

Figure 7: Effect of drainage on load transfer mechanism in tests with cyclic loading into tension with small compressive average stress, a) applied stress, b) total stress at lid invert, c) drainage at lid invert, d) effective load at lid invert. 
a)

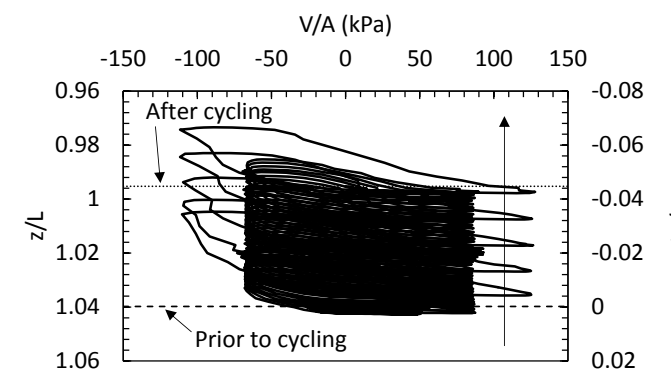

c)

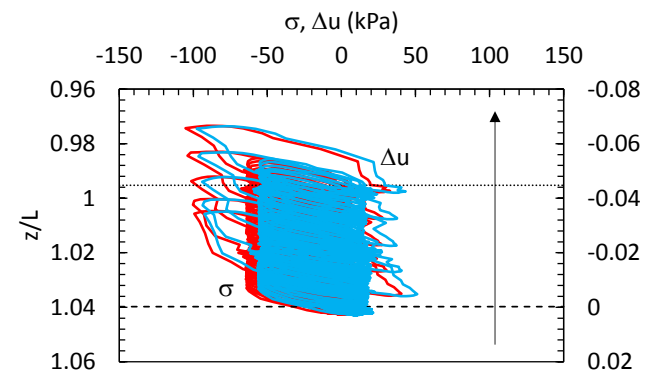

b)

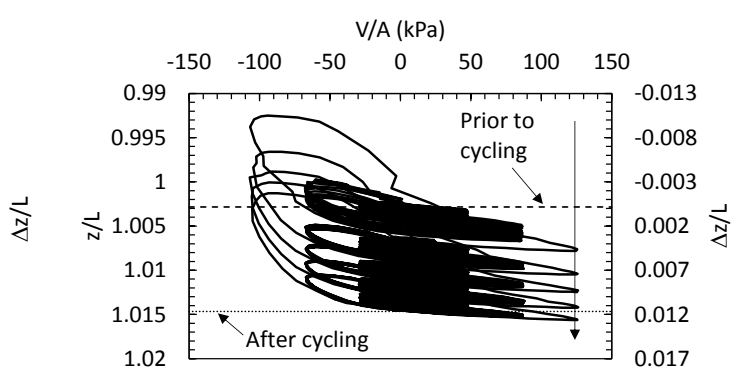

d)

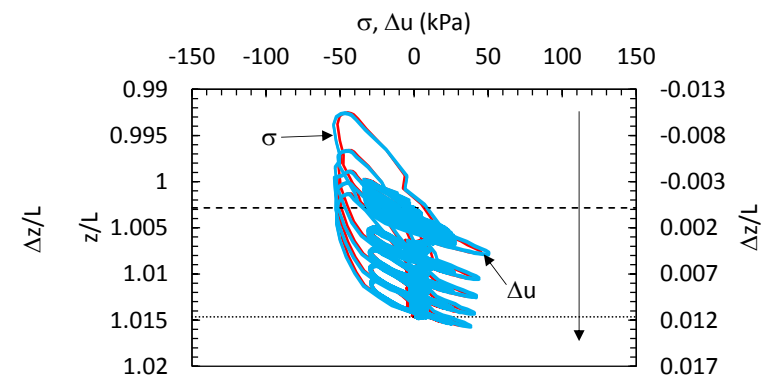

Figure 8: Caisson response over five cyclic loading sequences, applied stress, a) Test 42, b) Test 6-1; total stress and excess pore pressure at the lid invert, c) Test 4-2, d) Test 6-1. 
a)

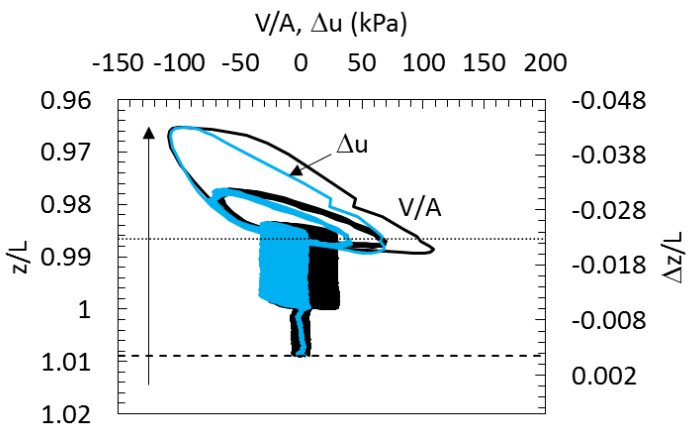

b)

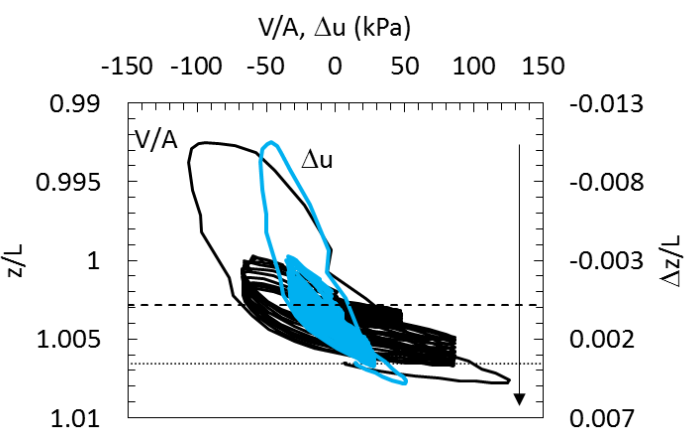

c)

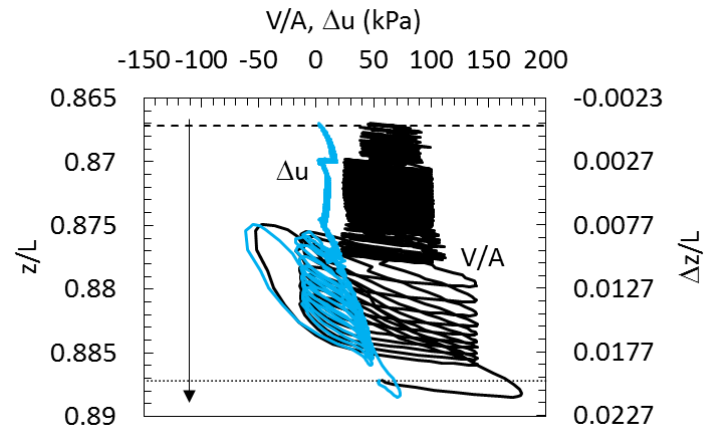

Figure 9: Effect of average stress, Tests a) 6-4, b) 6-1 and c) 6-5. 


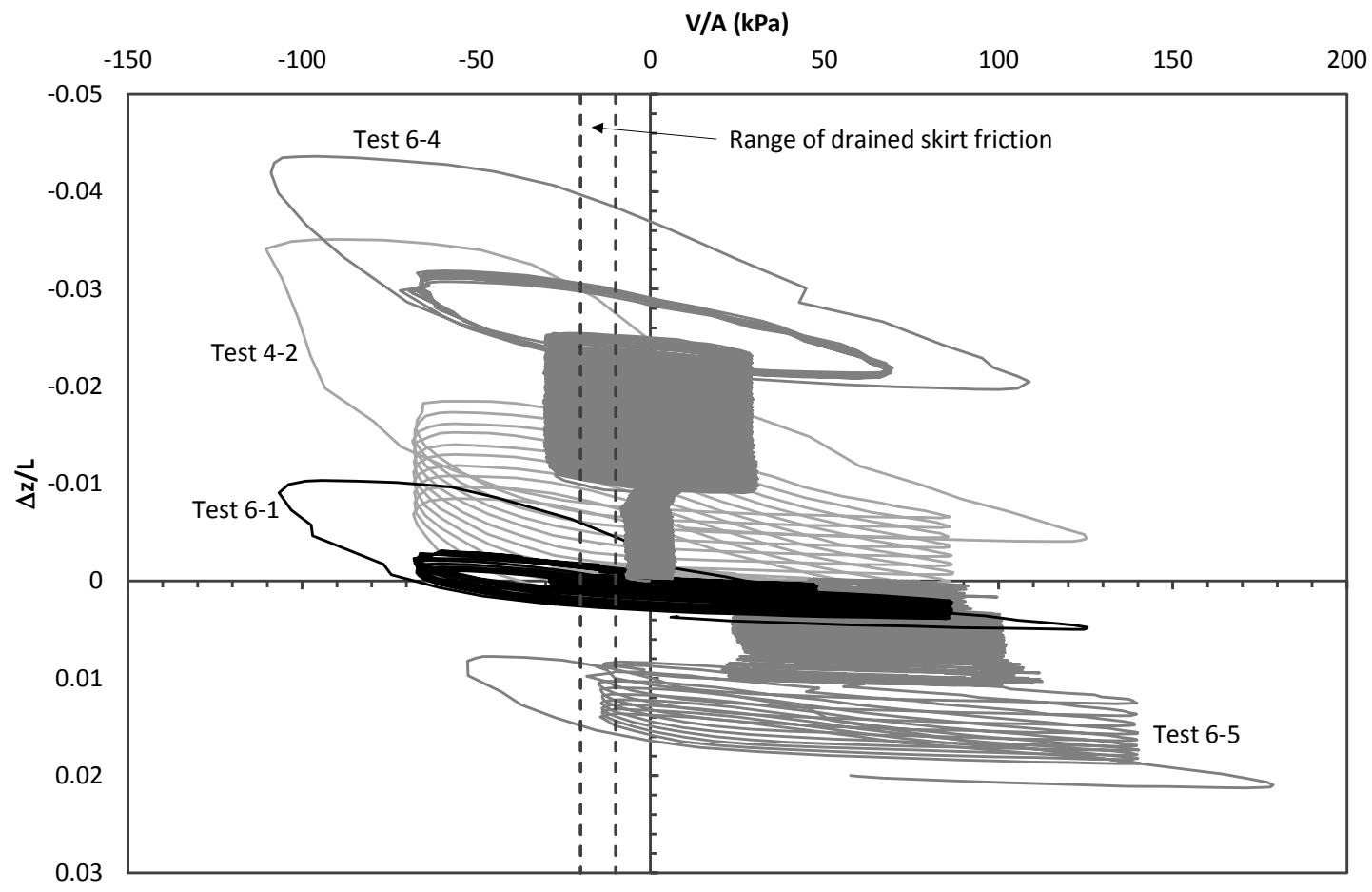

Figure 10: Comparison of tests with same cyclic sequence but different initial conditions. 
a)

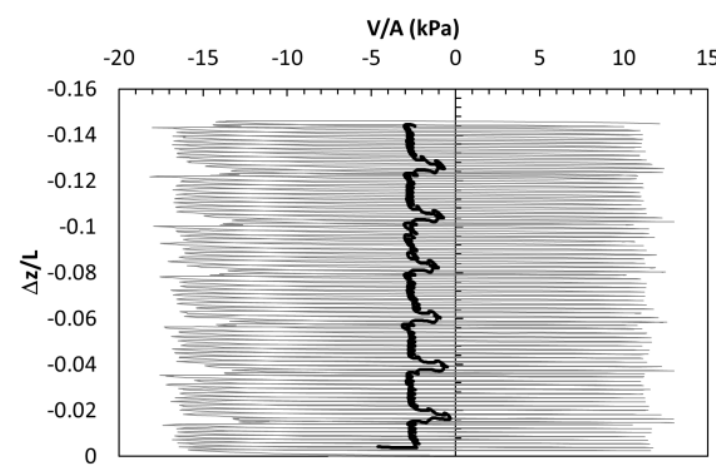

b)

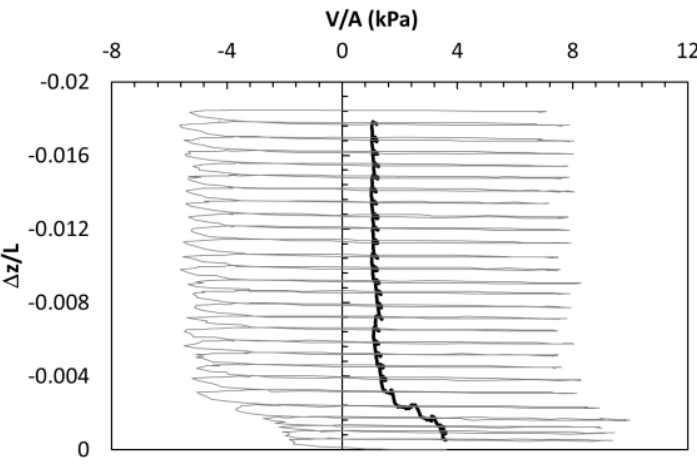

Figure 11: Cyclic loading with low amplitude and low average loads, a) Test 5-1, b) Test 5-3. Plotted on the figure is also the average load, taken as a moving average over two load cycles. 
a)
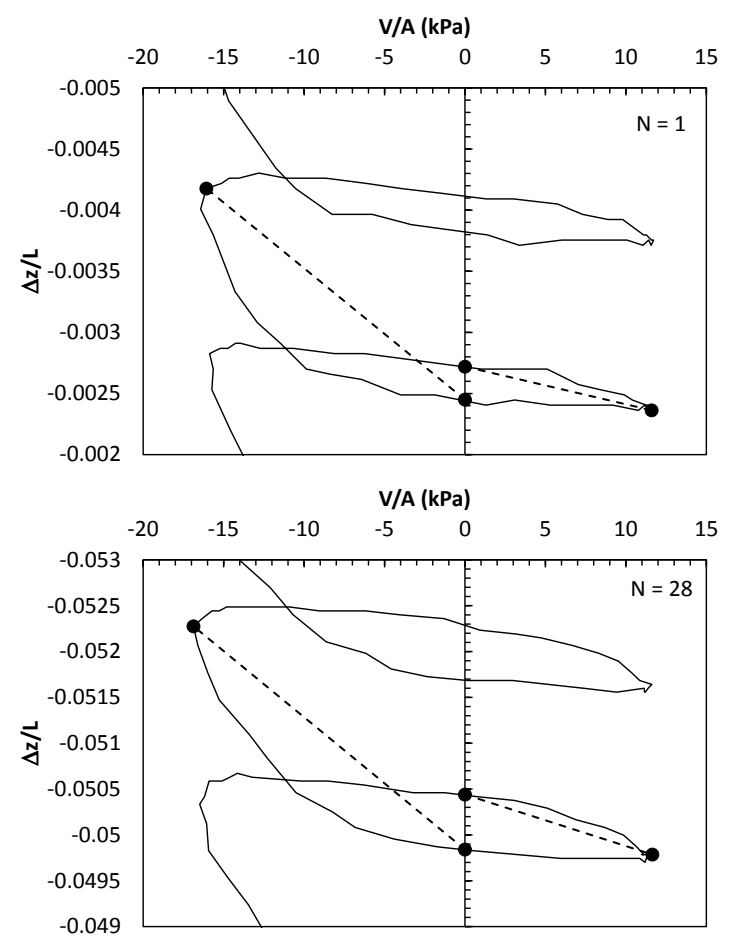

V/A ( $\mathrm{kPa})$

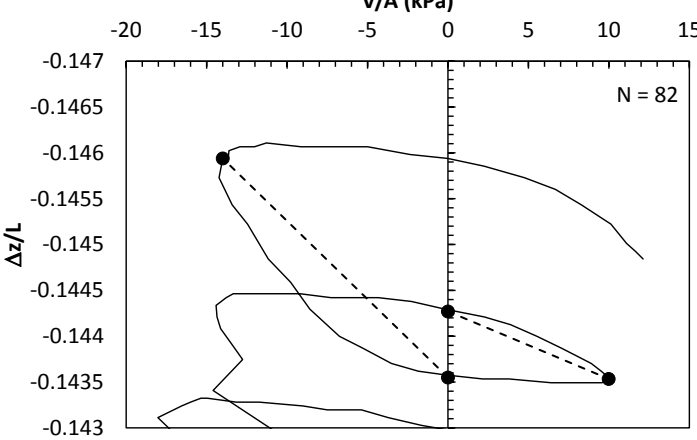

b)
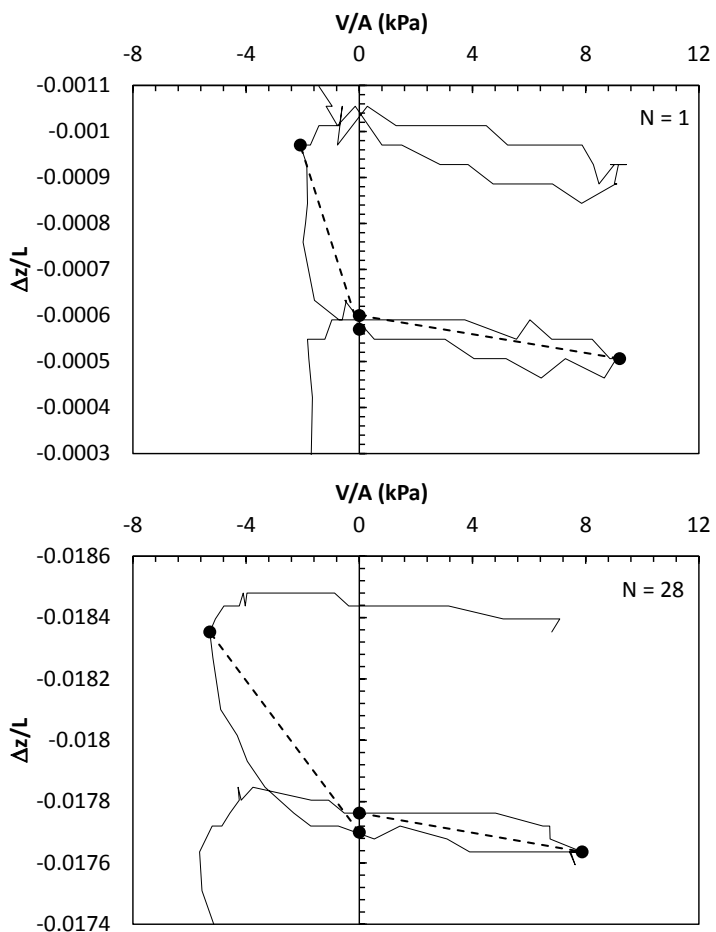

Figure 12: Evolution of stiffness in compression and tension, a) Test 5-1, b) Test 5-3. 
a)

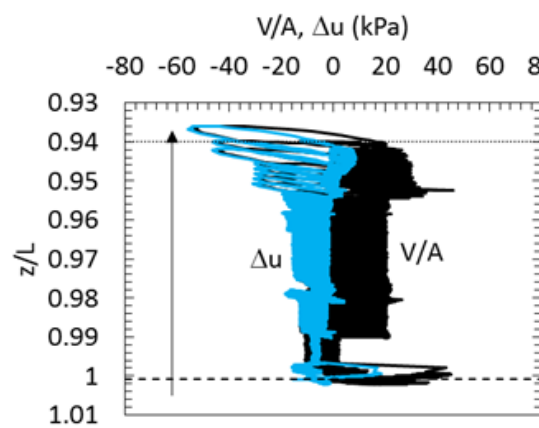

b)

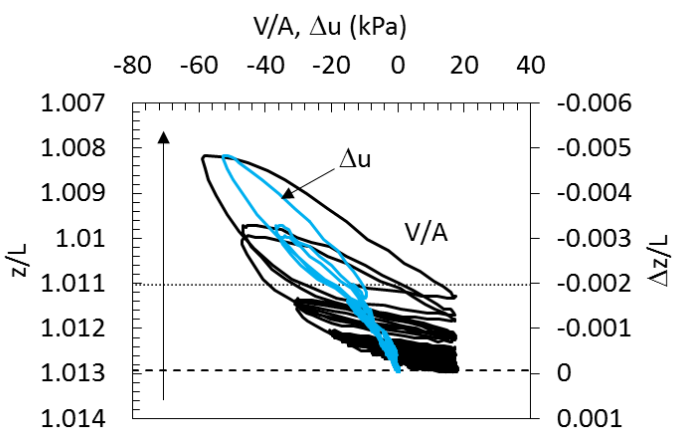

Figure 13: Response to 'Hansteen type' loading, a) Test 5-2, b) Test 6-2. 
a)

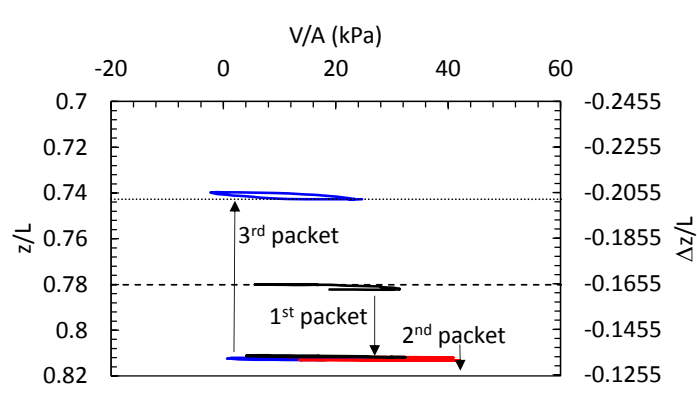

c)

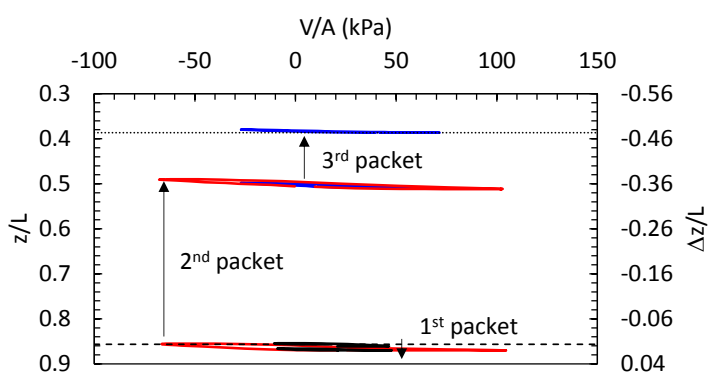

b)

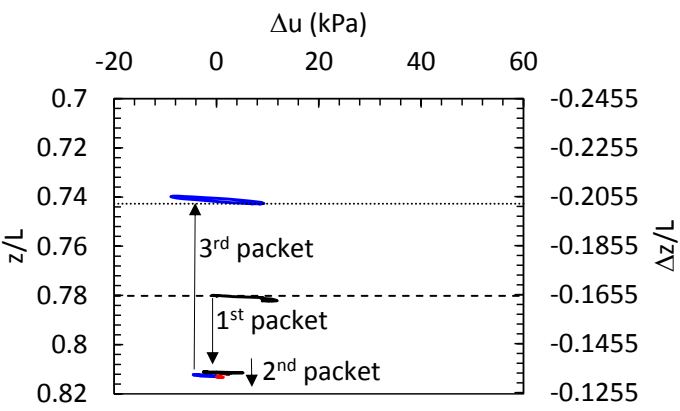

d)

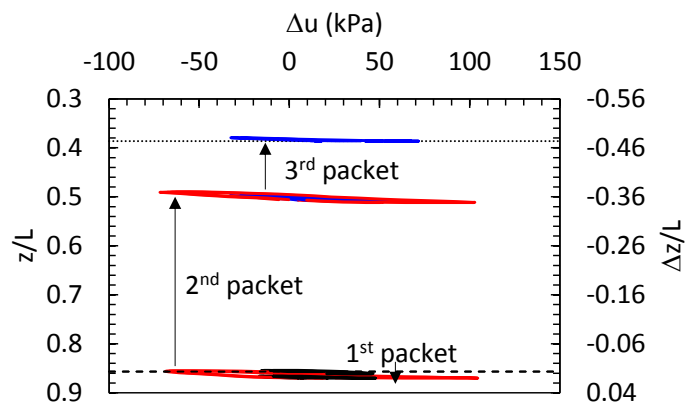

Figure 14: Test 5-1 (a, b) and 5-3 (c, d): applied stress (a, c), excess pore pressure at lid invert $(b, d)$. Data shown as first and last cycles of each packet. 


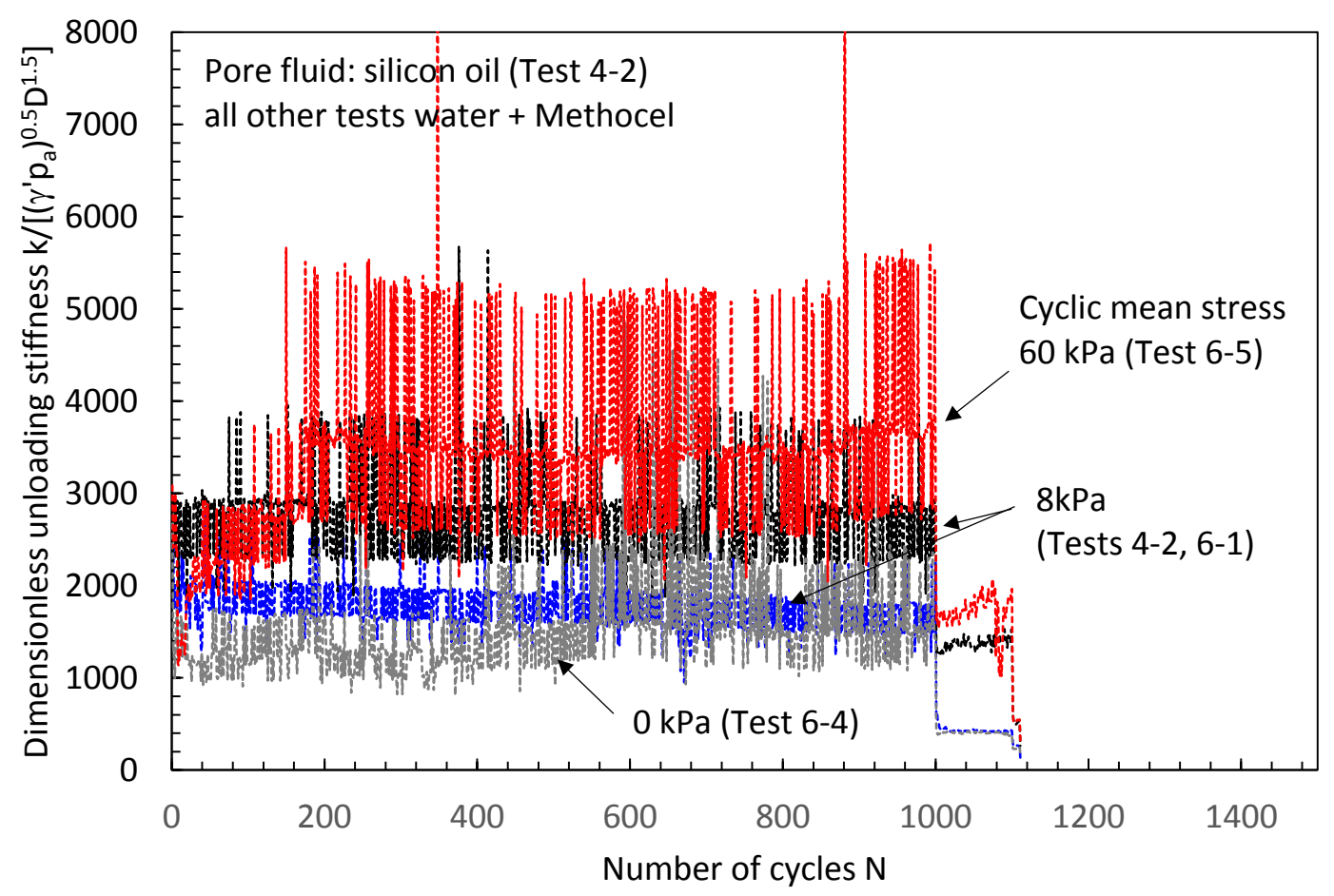

Figure 15: Effect on unloading stiffness of different average loads and drainage conditions. 